\title{
Aerosol Optical Characteristics from a Summer Campaign in an Urban Coastal Mediterranean Area
}

\author{
José A. Martínez-Lozano, M. Pilar Utrillas, Fernando Tena, Roberto Pedrós, Javier Cañada, José V. Boscá, and \\ Jerónimo Lorente
}

\begin{abstract}
We present a preliminary study of some optical properties of atmospheric aerosols over the area of Valencia, Spain, a coastal Mediterranean city. Measurements of spectral direct irradiance in the 300-1100 $\mathrm{nm}$ range were taken simultaneously at three sites: rural-continental, rural-coastal, and urban-coastal, all located within a $50 \mathrm{~km}$ radius of the city of Valencia. The irradiance measurements were obtained using three Li-cor 1800 spectroradiometers provided with radiance limiting tubes with field of views (FOVs) of $4.7^{\circ}$. The measurements were made under clear sky conditions during a field campaign carried out in the summer of 1998. In order to avoid the uncertainties associated with the determination of the water vapor content and the other atmospheric constituents, the analysis of the spectral aerosol optical thickness (AOT) values was limited to the $400-670 \mathrm{~nm}$ spectral band. From the values of the spectral AOT, both the Angstrom coefficients and the aerosol size distributions were obtained. The results show the great dependence of the optical aerosol characteristic on the direction of the prevailing winds (maritime or continental) in this area.
\end{abstract}

Index Terms-Aerosols, Angstrom coefficients, size distribution, spectral optical thickness.

\section{INTRODUCTION}

$\mathbf{R}$ ADIATIVE transfer codes (RTCs) and forcing radiative models (FRMs), which have been developed to assess climate change, incorporate algorithms based on standard aerosol models that are usually representative of the aerosols' radiative characteristics at large scales but do not necessarily faithfully reproduce the conditions at a particular location. Furthermore, although the seasonal mean aerosol optical properties that affect climate and remote sensing applications are remarkably consistent, day to day variations are large. Season and location are only partial predictors of aerosol optical properties, while the variation in aerosol size, for example, can vary significantly from day to day at a single location [22], [45]. These day-to-day variations stem from meteorological variability rather than direct changes in the strength of aerosol sources. In particular the residence time of a particular air mass and the duration of stagnant conditions will determine aerosol optical properties [46].

Manuscript received October 23, 2000; revised March 1, 2001. This work was supported in part by the Generalitat Valenciana (GV97-RN-14-18) and the Spanish Comisión Interministerial de Ciencia y Tecnología (CLI97-0345-C05).

J. A. Martínez-Lozano, M. P. Utrillas, F. Tena, and R. Pedrós are with the Departamento de Termodinámica, Universitat de Valencia, Valencia, Spain (e-mail: jmartine@uv.es).

J. Cañada is with the Departamento de Termodinámica Aplicada, Universitat Politécnica de Valencia, 46071 Valencia, Spain.

J. V. Boscà is with the Departamento de Física Aplicada, Universitat Politécnica de Valencia, 46071 Valencia, Spain.

J. Lorente is with the Departamento de Astronomía y Meteorología, Universitat de Barcelona, 08028 Barcelona, Spain.

Publisher Item Identifier S 0196-2892(01)05470-5.
The local variability in aerosol optical properties is especially dramatic when urban areas are considered. Large urban areas are often sources of extremely heavy pollution, affecting both the radiation balance and the climate for extensive regions around them. Comparison of the observed aerosol optical thickness with that calculated by the LOWTRAN7 code [31] in the Beijing area illustrates that the model overestimates the aerosol optical thickness (AOT) by up to $65 \%$ at $550 \mathrm{~nm}$ at high visibility levels and underestimates by about $35 \%$ at low visibility [32]. Utrillas et al. [57], from experimental irradiance measurements, have obtained for Valencia AOT values at $500 \mathrm{~nm}$ that present deviations of at least $15 \%$ of the RMSD value with respect to the boundary layer aerosol models implemented in the LOWTRAN7 [31] and the ZD-LOA [16], [17] RTCs. These results indicate that in many cases, the temporal variability of the aerosols makes discrimination between some of the aerosol models implemented in the RTCs very difficult partly because the aerosol models used are not the most appropriate for the types of aerosols actually present. Indeed, the aerosols are usually best represented by some combination of various standard types [55].

For these reasons, the determination of the physical and optical properties of aerosols in locations with different geographic characteristics and subject to different meteorological conditions is necessary and always welcome. Furthermore, for the new generation of satellites [30], [11] aerosol models that link aerosol properties to readily satellite-measured variable such as AOT are desirable [45]. At the present, aerosol characteristics can be obtained easily through the observation of the spectral AOT, which can be reliably determined using the passive spectral extinction method. Currently the AERONET network [23]. This is based on irradiance and sky radiance measurements in eight spectral bands, and filled the gap left after previous turbidity measurement networks whose results had been widely questioned [12], [60] were ended.

The AOT values over large urban areas are highly variable [33], [59], [32], [36], and this variability is particularly pronounced at coastal sites which are subject to changing land-sea breezes. The coastal zones represent a specific case of mixing. Marine aerosols generated occasionally at the sea surface by the interaction between wind and waves are added to continuous continental aerosols issued from natural and/or man-made sources [19], [41]. Furthermore, under certain conditions and due to an increase in relative humidity the size of an aerosol particle may increase by two to ten times its original dry size because the equilibrium size distribution of aerosols containing a fraction of soluble matter is modified by deliquescence [27], [24]. 
In this paper, we present the results of a preliminary analysis of some aerosol optical characteristics over the area of Valencia and its surroundings, an urban center on the Mediterranean (eastern) coast of the Iberian Peninsula with more than one million inhabitants. We limited the study to the spectral AOT and the aerosol size distribution functions. The results are representative of typical synoptic summer conditions in this region, and were obtained by measuring solar irradiance at ground level using spectroradiometers. Measurements were taken at three different locations: 1) the city center, 2) a rural site $30 \mathrm{~km}$ to the south, protected from the influence of the urban aerosols by the predominant easterly winds, and 3) a site distant from both the sea and the urban center, located at $50 \mathrm{~km}$ to the northwest of the city and at an altitude of $600 \mathrm{~m}$ above sea level.

\section{Measurement CAmpaign And Methodology}

The city of Valencia is located on the Spanish east coast $\left(39.5^{\circ} \mathrm{N}, 0.5^{\circ} \mathrm{W}\right)$. The metropolitan area has a population of 1.3 million inhabitants and includes a number of metallurgical, wood and paper processing, and chemical industries. The climate is Mediterranean with anticyclonic conditions and persistently high solar radiation during the summer months. The accumulated insolation registered yearly at Valencia is greater than $2600 \mathrm{~h}$ according to the last reference year [34]. Coastal mountain ranges isolate the Valencia basin, forming a semicircle with a radius of approximately $25 \mathrm{~km}$. The coastal ranges act as a natural barrier to the sea breeze transport and maritime aerosols could be gradually transformed by the urban environment [58], [41].

Three observation sites were selected for the experimental measurements. The first, in the city center, is exposed to the aerosols emitted in the urban area and those coming from the sea. A second was set up at $30 \mathrm{~km}$ to the south of the center of the city in the Albufera Natural Park, close to the sea, free of buildings and, presumably outside the city's influence since the prevailing winds are southeasterly. The third measurement point was at $50 \mathrm{~km}$ northwest of the city, in the outskirts of Chulilla, a small town at $600 \mathrm{~m}$ above sea level with no industry apart from rural tourism.

Spectral solar irradiance measurements were obtained using three Li-cor 1800 spectroradiometers. The Li-cor 1800 is a spectroradiometer provided with a simple monochromator that allows us to obtain measurements in the range 300-1100 nm with a FWHM of $6 \mathrm{~nm}$ approximately and a wavelength step of $1 \mathrm{~nm}$. For the direct irradiance measurements, a radiance-limiting tube (collimator) was used with a FOV of $4.7^{\circ}$. Several papers have studied the sensitivity of this model of spectroradiometer which varies depending on the spectral range considered [48], [40], [33], [8]. The greatest errors (around 20\%) correspond to the UV region, due to the greater calibration error in this band and the degradation of the Teflon diffuser. In the visible and near-infrared regions (400-1000 nm) the measurement error, governed mainly by the calibration uncertainty, is $5 \%$, while in the range between 1000 and $1100 \mathrm{~nm}$ the error can increase significantly because of the sensitivity of the spectroradiometer to temperature.

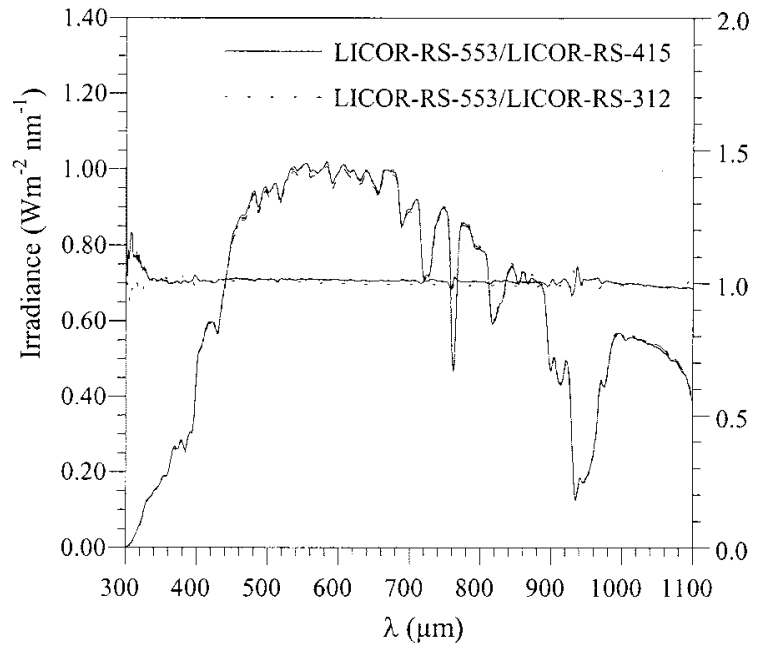

Fig. 1. Spectral direct irradiance at normal incidence obtained simultaneously for the three Li-cor spectroradiometers on 06/18/98 (optical mass 1.4).

The Li-cor spectroradiometers used in this work have serial numbers: RS-312 (Universitat de Barcelona), RS-415 (Universitat de Valencia, Valencia, Spain), and RS-553 (Universidad Politecnica de Valencia, Valencia, Spain). They were calibrated before and after the measurement campaign using an absolute calibration lamp (Li-cor optical radiation calibrator) in the Thermodynamics Department, University of Valencia. Before the measurement campaign, simultaneous measurements were made with all three spectroradiometers to establish whether it was necessary to perform any corrections between them. Shown in Fig. 1, by way of example, are the spectral curves registered for an optical air mass of 1.4. The deviations between the measurements of the three instruments in the visible range, which was the range used in this work, were very small and always less than the $3 \%$ precision given by these instruments for this spectral range. The rest of the measurements made to compare the instruments presented similarly small deviations.

Before starting the measurement campaign, a series of control measurements were made simultaneously at different points in the city of Valencia in order to establish whether the location within the city could affect the measurements' representativity. This exercise showed that the differences between the measurements at different points were negligible. In these circumstances, and to facilitate the measurements, the roof of the Upper School of Industrial Engineering of the Polytechnic University of Valencia, located on the edge of the city and with a horizon free of obstacles, was used. Fig. 2 compares spectral curves for direct irradiance obtained simultaneously at this point and at one of the busiest traffic junctions in the center of the city.

The field measurement campaign ran from June 22, 1998 to July 10, 1998. The measurements were taken every half-hour and simultaneously at the three sites from 7:00 to 16:00 solar time. Only measurements corresponding to the six days in this period for which clear skies were found throughout the day for all three sites have been considered in the analysis. The typical synoptic weather pattern for the area of Valencia in summer is characterized by a combination of high pressure due to the Azores anticyclone and a relative thermal low originating in North Africa. This produces light easterly and southeasterly 


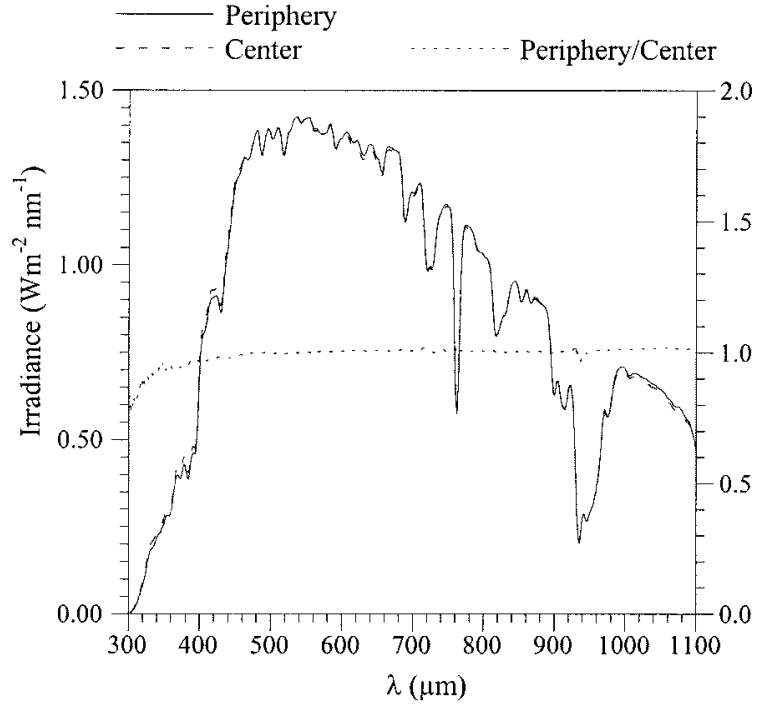

Fig. 2. Spectral direct irradiance at normal incidence obtained at the center of the city of Valencia and on the periphery of the urban area on February 12, 1998 (optical mass 1.7).

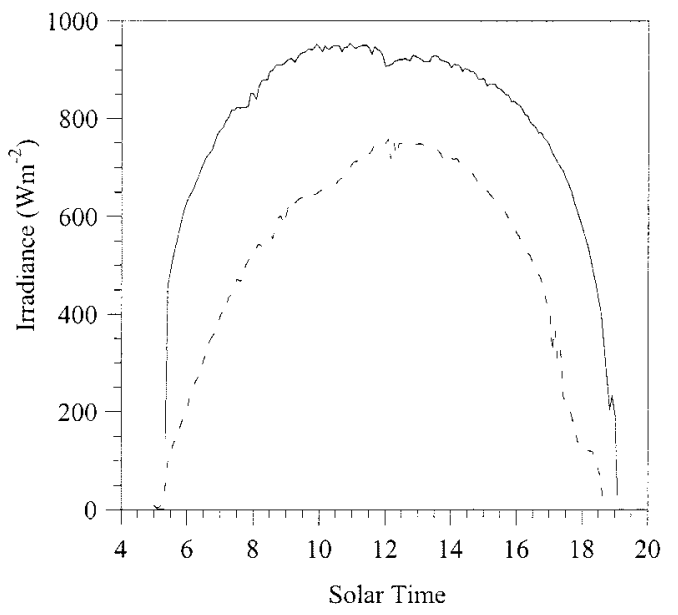

Fig. 3. Daily evolution of the integrated direct irradiance at normal incidence for July 6, 1998 (- -) and July 3, 1998 (-) in Valencia.

winds with relative humidity of over $50 \%$, which cause hazy mornings and occasional cloud formation in the late afternoon. Five of the six clear days were typical in this respect. However the sixth day presented very different conditions with a continental northwesterly wind, which cleaned the atmosphere, and very low values of relative humidity. For this reason, we have chosen to present here the results for just two days: 1) the atypical day, July 3, 1998; and 2) another day soon afterwards, July 6,1998 , representative of the prevailing conditions in the Valencia area in the summer. The difference in sky clearness between these two days can be seen in Fig. 3, in which the daily evolution of integrated direct normal irradiance is shown for both days. These irradiance values were registered using an Eppley NIP pyrheliometer at the automatic solar radiation station of the Upper School of Industrial Engineering. The figure shows that on the July 3, 1998 the direct irradiance was about a 20\% higher than for the July 6, 1998.
The total atmospheric optical thickness $\tau_{T \lambda}$ was determined from the spectral irradiance measurements $E_{n \lambda}$, using the Bouger-Lambert-Beer exponential law

$$
E_{n \lambda}=\left(1 / \rho^{2}\right) E_{0 \lambda} \exp \left(-\tau_{T \lambda} m\right)
$$

where

$\rho \quad$ mean relative Earth-Sun distance;

$E_{0 \lambda}$ incident solar flux at the top of the atmosphere measured at the mean Earth-Sun distance;

$m$ relative optical air mass.

Although our spectral measurements range from $300 \mathrm{~nm}$ to $1100 \mathrm{~nm}$, in this work, we have limited the study of the spectral AOT to the 400-670 nm band, where the only gaseous components that show nonnegligible absorption are ozone (Chappuis band) and $\mathrm{NO}_{2}$. Using this band allows us to ignore uncertainties in the absorption characteristics and column amounts of other molecules, particularly $\mathrm{H}_{2} \mathrm{O}$.

For the $400-670 \mathrm{~nm}$ band the total optical thickness becomes

$$
\tau_{T \lambda}=\tau_{R \lambda}+\tau_{a \lambda}+\tau_{O \lambda}+\tau_{N \lambda} .
$$

where

$$
\begin{array}{ll}
\tau_{R \lambda} & \begin{array}{l}
\text { molecular scattering optical thickness } \\
\text { (Rayleigh scattering); }
\end{array} \\
\tau_{a \lambda} & \text { AOT; } \\
\tau_{O \lambda} \text { and } \tau_{N \lambda} & \begin{array}{l}
\text { optical thickness due to } \mathrm{O}_{3} \text { and } \mathrm{NO}_{2} \text { ab- } \\
\text { sorption, respectively. }
\end{array}
\end{array}
$$

Once the total atmospheric optical thickness has been determined, the values of the AOT $\tau_{a \lambda}$ may be obtained by eliminating from $\tau_{T \lambda}$ the contributions due to Rayleigh scattering and to absorption by the other atmospheric components.

The $\tau_{T \lambda}$ values were determined by fitting experimental irradiance data to optical mass using equation (1) with the of $E_{0 \lambda}$ values proposed by the SMARTS2 code [20] and the empirical expression for the air mass suggested by Kasten and Young [25]. The $E_{0 \lambda}$ spectral data have been smoothed to the field of view and bandpass of our spectroradiometer employing the Gaussian approximation.

In order to obtain the AOT, $\tau_{a \lambda}$, the ozone absorption coefficients from Anderson and Mauersberger [1] were assumed. The ozone content was measured in Madrid (350 km from Valencia) and Murcia ( $250 \mathrm{~km}$ from Valencia) by the INM (National Meteorological Institute, personal communication) using Brewer spectroradiometers. $\mathrm{NO}_{2}$ was modeled using absorption coefficients from Davidson et al. [9] in the 400-600 nm and from Schneider et al. [52] in the 600-670 nm band. For $\mathrm{NO}_{2}$ content, the reference atmosphere proposed by the LOWTRAN7 code [31] has been considered, specifically, the effective path length of $\mathrm{NO}_{2}$ for midlatitude summer. For Rayleigh scattering the recently proposed approximation of Bodhaine et al. [4] has been used.

The main error sources in the AOT values are the air mass determination, the accuracy characterization of the transmission curve of the interference filters, the circumsolar irradiance (due to the finite FOV), and the solar irradiance at the top of the atmosphere if the Langley plots are used [10]. Taking into account these error sources and the works of Russell et al. [49] and 
TABLE I

Aerosol Optical Thickness $\left(\tau_{a}\right)$ for July 6, 1998. 1) Valencia City Center; 2) Albufera Natural Park; 3) And Chulilla

\begin{tabular}{cc|ccc|ccc|ccc}
\hline $\begin{array}{c}\text { Solar } \\
\text { Time }\end{array}$ & $\begin{array}{c}\text { Humidity } \\
(\%)\end{array}$ & \multicolumn{3}{c|}{$\begin{array}{c}\text { Site } 1 \\
\tau_{\mathrm{a}}(400 \mathrm{~nm})\end{array}$} & $\tau_{\mathrm{a}}(550 \mathrm{~nm})$ & $\tau_{\mathrm{a}}(670 \mathrm{~nm})$ & $\tau_{\mathrm{a}}(400 \mathrm{~nm})$ & $\begin{array}{c}\text { Site } 2 \\
\tau_{\mathrm{a}}(550 \mathrm{~nm})\end{array}$ & $\tau_{\mathrm{a}}(670 \mathrm{~nm})$ & \multicolumn{3}{c}{$\begin{array}{c}\text { Site } 3 \\
\tau_{\mathrm{a}}(400 \mathrm{~nm})\end{array}$} & $\tau_{\mathrm{a}}(550 \mathrm{~nm})$ & $\tau_{\mathrm{a}}(670 \mathrm{~nm})$ \\
\hline $7: 30$ & 58.0 & 0.50 & 0.39 & 0.37 & 0.46 & 0.38 & 0.36 & 0.37 & 0.33 & 0.33 \\
$8: 00$ & 52.5 & 0.47 & 0.39 & 0.37 & 0.45 & 0.38 & 0.36 & 0.36 & 0.33 & 0.33 \\
$8: 30$ & 50.2 & 0.49 & 0.40 & 0.39 & 0.53 & 0.42 & 0.39 & 0.37 & 0.34 & 0.34 \\
$9: 00$ & 52.9 & 0.46 & 0.37 & 0.37 & 0.46 & 0.38 & 0.37 & 0.39 & 0.35 & 0.35 \\
$9: 30$ & 55.1 & 0.47 & 0.38 & 0.37 & 0.45 & 0.37 & 0.37 & 0.42 & 0.38 & 0.38 \\
$10: 00$ & 55.2 & 0.50 & 0.40 & 0.39 & 0.44 & 0.37 & 0.36 & 0.42 & 0.38 & 0.38 \\
$10: 30$ & 63.0 & 0.48 & 0.40 & 0.39 & 0.44 & 0.38 & 0.37 & 0.42 & 0.38 & 0.39 \\
$11: 00$ & 60.0 & 0.44 & 0.36 & 0.36 & 0.46 & 0.39 & 0.38 & 0.41 & 0.36 & 0.36 \\
$11: 30$ & 61.0 & 0.43 & 0.35 & 0.34 & 0.41 & 0.32 & 0.32 & 0.40 & 0.34 & 0.34 \\
$12: 00$ & 63.7 & 0.39 & 0.30 & 0.30 & 0.40 & 0.32 & 0.32 & 0.38 & 0.31 & 0.31 \\
$12: 30$ & 52.9 & 0.44 & 0.32 & 0.30 & 0.39 & 0.32 & 0.32 & 0.39 & 0.32 & 0.31 \\
$13: 00$ & 56.5 & 0.37 & 0.29 & 0.29 & 0.38 & 0.30 & 0.30 & 0.47 & 0.36 & 0.34 \\
$13: 30$ & 57.6 & 0.37 & 0.29 & 0.29 & 0.38 & 0.30 & 0.30 & 0.47 & 0.36 & 0.34 \\
$14: 00$ & 58.2 & 0.38 & 0.30 & 0.29 & 0.39 & 0.31 & 0.31 & 0.48 & 0.36 & 0.34 \\
$14: 30$ & 58.4 & 0.38 & 0.30 & 0.28 & 0.40 & 0.32 & 0.32 & 0.43 & 0.34 & 0.32 \\
$15: 00$ & 62.0 & 0.39 & 0.31 & 0.30 & 0.42 & 0.34 & 0.32 & 0.39 & 0.31 & 0.30 \\
$15: 30$ & 65.0 & 0.40 & 0.31 & 0.30 & 0.42 & 0.34 & 0.32 & 0.38 & 0.30 & 0.29 \\
$16: 00$ & 65.0 & 0.41 & 0.32 & 0.30 & 0.40 & 0.32 & 0.31 & 0.38 & 0.31 \\
\hline
\end{tabular}

TABLE II

Aerosol Optical Thickness ( $\tau_{a}$ ) for July 3, 1998. 1) Valencia City Center; 2) Albufera Natural Park; and 3) Chulilla

\begin{tabular}{cc|ccc|ccc|ccc}
\hline $\begin{array}{c}\text { Solar } \\
\text { Time }\end{array}$ & $\begin{array}{c}\text { Humidity } \\
(\%)\end{array}$ & \multicolumn{3}{c|}{$\begin{array}{c}\text { Site } 1 \\
\tau_{\mathrm{a}}(400 \mathrm{~nm})\end{array}$} & $\left.\tau_{\mathrm{a}} 550 \mathrm{~nm}\right)$ & $\tau_{\mathrm{a}}(670 \mathrm{~nm})$ & $\tau_{\mathrm{a}}(400 \mathrm{~nm})$ & $\begin{array}{c}\text { Site } 2 \\
\left.\tau_{\mathrm{a}} 550 \mathrm{~nm}\right)\end{array}$ & $\tau_{\mathrm{a}}(670 \mathrm{~nm})$ & \multicolumn{3}{c}{$\begin{array}{c}\text { Site } 3 \\
\tau_{\mathrm{a}}(400 \mathrm{~nm})\end{array}$} & $\left.\tau_{\mathrm{a}} 550 \mathrm{~nm}\right)$ & $\tau_{\mathrm{a}}(670 \mathrm{~nm})$ \\
\hline $7: 30$ & 33.0 & 0.10 & 0.07 & 0.07 & 0.11 & 0.08 & 0.08 & 0.05 & 0.04 & 0.05 \\
$8: 00$ & 33.2 & 0.14 & 0.08 & 0.08 & 0.11 & 0.07 & 0.08 & 0.06 & 0.05 & 0.06 \\
$8: 30$ & 33.2 & 0.11 & 0.07 & 0.08 & 0.11 & 0.07 & 0.08 & 0.06 & 0.05 & 0.06 \\
$9: 00$ & 29.0 & 0.10 & 0.06 & 0.07 & 0.12 & 0.08 & 0.09 & 0.06 & 0.05 & 0.06 \\
$9: 30$ & 26.6 & 0.10 & 0.06 & 0.07 & 0.14 & 0.10 & 0.11 & 0.07 & 0.05 & 0.07 \\
$10: 00$ & 25.3 & 0.10 & 0.07 & 0.09 & 0.15 & 0.11 & 0.11 & 0.07 & 0.05 & 0.07 \\
$10: 30$ & 24.0 & 0.12 & 0.07 & 0.08 & 0.13 & 0.09 & 0.10 & 0.07 & 0.05 & 0.07 \\
$11: 00$ & 22.1 & 0.13 & 0.09 & 0.10 & 0.13 & 0.09 & 0.09 & 0.07 & 0.05 & 0.07 \\
$11: 30$ & 22.6 & 0.15 & 0.10 & 0.12 & 0.14 & 0.10 & 0.10 & 0.07 & 0.06 & 0.07 \\
$12: 00$ & 23.2 & 0.17 & 0.10 & 0.10 & 0.14 & 0.10 & 0.12 & 0.08 & 0.06 & 0.08 \\
$12: 30$ & 27.5 & 0.17 & 0.11 & 0.11 & 0.14 & 0.09 & 0.10 & 0.07 & 0.06 & 0.08 \\
$13: 00$ & 43.0 & 0.17 & 0.10 & 0.11 & 0.16 & 0.12 & 0.13 & 0.09 & 0.07 & 0.09 \\
$13: 30$ & 46.7 & 0.15 & 0.10 & 0.11 & 0.14 & 0.10 & 0.10 & 0.09 & 0.07 & 0.08 \\
$14: 00$ & 48.1 & 0.14 & 0.09 & 0.09 & 0.16 & 0.12 & 0.13 & 0.08 & 0.06 & 0.08 \\
$14: 30$ & 48.6 & 0.14 & 0.09 & 0.10 & 0.15 & 0.12 & 0.13 & 0.08 & 0.06 & 0.07 \\
$15: 00$ & 52.4 & 0.14 & 0.09 & 0.09 & 0.13 & 0.09 & 0.10 & 0.07 & 0.06 & 0.07 \\
$15: 30$ & 52.7 & 0.14 & 0.09 & 0.09 & 0.13 & 0.09 & 0.09 & 0.09 & 0.07 & 0.08 \\
$16: 00$ & 50.3 & 0.14 & 0.09 & 0.09 & 0.13 & 0.10 & 0.10 & 0.12 & 0.10 \\
\hline
\end{tabular}

Dutton et al. [12], Utrillas [56] developed a simplified method to estimate the error associated to the AOT values retrieval from spectral irradiance measurements. The error values associated to $\tau_{T \lambda}$ gives approximately

$$
\varepsilon\left(\tau_{T \lambda}\right)=\frac{1}{m}\left(\frac{\varepsilon\left(E_{n \lambda}\right)}{E_{n \lambda}}+0.001\right)
$$

The $\varepsilon\left(\tau_{T \lambda}\right)$ values obtained from (3) are similar to those presented by Kaufman et al. [26], who obtain values between 0.01 and 0.02 .

\section{RESUlTS AND DisCUSSION}

\section{A. Spectral Aerosol Optical Thickness}

The results presented here are those obtained by the method described above from experimental values of direct irradiance at normal incidence registered on July 3, 1998 and July 6, 1998 at the three measurement sites. In the following these sites are referred to by a number: 1) Valencia City Center (Upper School of Industrial Engineering); 2) Albufera Natural Park (Center for the Protection and Study of the Natural Environment); and 3) Chulilla (Mountain Hostel). Tables I (July 6, 1998) and II (July 3,1998 ) show the evolution of the aerosol optical thickness for the measurement sites for the two days. In order to simplify their presentation the results are shown for just three selected wavelengths, $400 \mathrm{~nm}, 550 \mathrm{~nm}$, and $670 \mathrm{~nm}$. The $550 \mathrm{~nm}$ has been chosen because it is usually taken as a reference wavelength when using sun photometers. The $400 \mathrm{~nm}$ and $670 \mathrm{~nm}$ wavelength are the limits of the measurement ranges used in the analysis. The tables also show the values of relative humidity taken at the measurement site 1, which are not strictly applicable to the other two stations. The values for sea level pressure, not shown in the tables, were $1011 \mathrm{mb}$ for July 6, 1998, and $1015 \mathrm{mb}$ for 
July 3, 1998. From the AOT values and based on the classification of Lorente et al. [33], July 3, 1998 was a day with very clear air (AOT at $500 \mathrm{~nm}$ less than 0.2). Similarly, July 6, 1998 was a day with moderately turbid air (AOT at $500 \mathrm{~nm}$ between 0.35 and 0.45 ). The latter is the most frequent situation in the study area during summer [42].

Tables I and II show that big differences in the AOT values were found for the two days. The wind direction, not given in the tables, may explain most of the differences in the AOT values for these days. For July 6, 1998 (Table I) the wind at the three sites was southeast (maritime) throughout the day. Except for July 3, 1998, these are the same conditions observed on every other day of the measurement campaign. As has already been stated, these wind conditions are typical for the region around Valencia during the summer. It can be observed that stations 1 and 2 present very similar results, both for the value of the AOT and for its evolution. It would seem to be difficult, based solely on an analysis of the AOT, to distinguish between the aerosol characteristics over the city center site 1 and over the site 2 located near the sea. The AOT values show a slow decrease throughout the day to reach a minimum around 14:00 $\mathrm{h}$ before a slight increase later. This pattern could be explained by the presence of morning mist. The humidity values, although high, never pass $65 \%$, so a change in the composition of the urban aerosols would not be expected [24]. However these humidity values are surface values. Not information concerning moisture aloft is available, and of course AOT is a total column measure that depends on humidity through the whole column. The increase in relative humidity could explain the slight increase in optical thickness that is detected in these days for the last measurements of the afternoon. For point number 3, the daily evolution of the AOT values is different, reaching a maximum in the middle of the day. It was impossible to establish any hypothesis to explain this evolution in relation to the relative humidity since no measurements of this were available at the measurement site for the days of the campaign. In general, we can conclude that there was little difference between the AOT values obtained for the three locations and that, under these wind conditions, the results for the metropolitan area of Valencia could be extrapolated, with a small margin of error, to a region with a $50 \mathrm{~km}$ radius. The presence of maritime winds seems to make the atmospheric conditions more uniform in this area at such a small scale.

For July 3, 1998 (Table II) the wind measured in the rural site 3 ) was westerly (continental) for 24 hours. In the coastal sites (1 and 2), the wind was westerly from 0:00 h to 12:00 $\mathrm{h}$ when it veered slowly to the east. From 14:00 h, it continued in the east direction to change brusquely once again at 19:00 hours toward the north. This change in wind direction was not reflected in the AOT values. For sites 1 and 2, the AOT values were similar and noticeably less by about 30 to $50 \%$ for site 3 . The westerly wind caused a significant drop in the relative humidity and, in turn, exceptionally low AOT values at the three points. At the city center, the AOT values at $550 \mathrm{~nm}$ varied between 0.07 and 0.11 , which are similar to the lowest values found over the past five years [36]. The continental wind cleans the sky over Valencia and does not permit the intrusion of aerosols from the sea. This effect persists even several hours after the wind had veered, although the change of wind direction does lead to a rapid increase in relative humidity which rose from $27.5 \%$ to $45 \%$ at 13:00 h.

\section{B. Parameterization of the AOT. Angstrom Coefficients}

Tables I and II give only a partial vision of the spectral characteristics of the AOT for July 3, 1998 and July 6, 1998 since they only include the values for 3 wavelengths. Fig. 4 gives more information on the wavelength dependence of AOT, showing typical curves of spectral AOT for the 400-670 nm range for 9:00, 12:00, and 15:00 TST. Two features are clearly seen: a) the AOT values for July 6, 1998 (maritime wind) are far higher that those of July 3, 1998 (continental wind); b) the shape of the curves of AOT versus wavelength is very different from one day to the other, with a much more pronounced gradient for July 6, 1998 that indicates the presence of different types of aerosols.

We have analyzed the dependence of the AOT with the wavelength employing the power law relationship proposed by Angstrom [2], [3]

$$
\tau_{a \lambda}=\beta \lambda^{-\alpha}
$$

where $\lambda$ is the wavelength expressed in micrometers. The turbidity coefficient $\beta$ is the aerosols' extinction coefficient corresponding to the $1 \mu \mathrm{m}$ wavelength. This coefficient is related to the amount of aerosols present in the atmosphere, and it is widely used in meteorological observations to characterize the degree of air pollution or turbidity. The wavelength exponent $\alpha$ is related to the aerosols' size distribution, and is a first rough assessment of the aerosol characteristics, for instance, the effective radius. According Higurashi and Nakajima [21] the characteristic dependence of the Angstrom exponent on the aerosol optical thickness is caused by a correlation between the accumulation mode and the large coarse particle mode attributed to soil or ash particles.

Nevertheless, it is worth remembering that the Angstrom formula is only a convenient approximation, not necessarily valid over an extended spectral range. Our analysis has only been carried out for the 400-670 $\mathrm{nm}$ band and the results obtained may not be extrapolated to other spectral bands where the presence of water vapor and other atmospheric constituents may affect the results considerably. To obtain values of $\alpha$ and $\beta$ we have directly adjusted (4) for each of the series of spectral measurements. This direct fit produces errors slightly lower that when a $\log -\log$ fit is used for this spectral range [35]. Errors associated with $\alpha$ and $\beta$ values have been obtained by applying the propagation error method to (4). The errors obtained in the determination of the turbidity coefficient $\beta$ were about 0.03 and in the determination of the wavelength exponent $\alpha$, about 0.07 . The fitting parameters corresponding to maritime wind conditions (July 6, 1998) give correlation coefficients $(r)$ that are reasonable for site 3 (0.65 to 0.95 ) and good for sites 1 (0.80 to 0.95) and 2 ( 0.80 to 0.95$)$. However those corresponding to the continental wind conditions (July 3, 1998) are rather low, especially for site 3 (0.05 to 0.50$)$.

The Angstrom parameters that work properly in a given wavelength range might not be so appropriate in another [6], [7], [35]. Therefore, and given the curves shown in Fig. 4, we chose to carry out new independent adjustments for each of the spectral subintervals, $400-550 \mathrm{~nm}$ and $550-670 \mathrm{~nm}$. In the spectral subinterval 400-550 $\mathrm{nm}$ the correlation coefficients $(r)$ take values within the ranges $0.93-0.98$ (site 1), $0.91-0.98$ (site 2), 


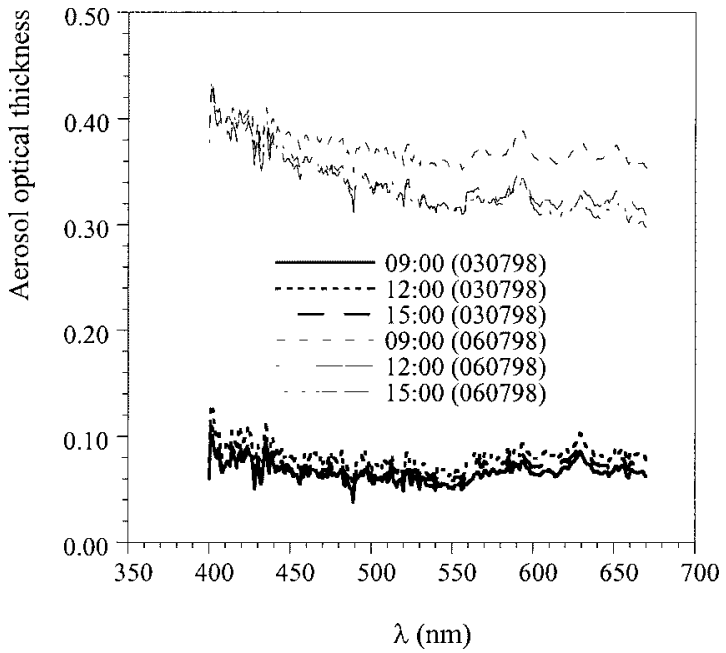

(a)

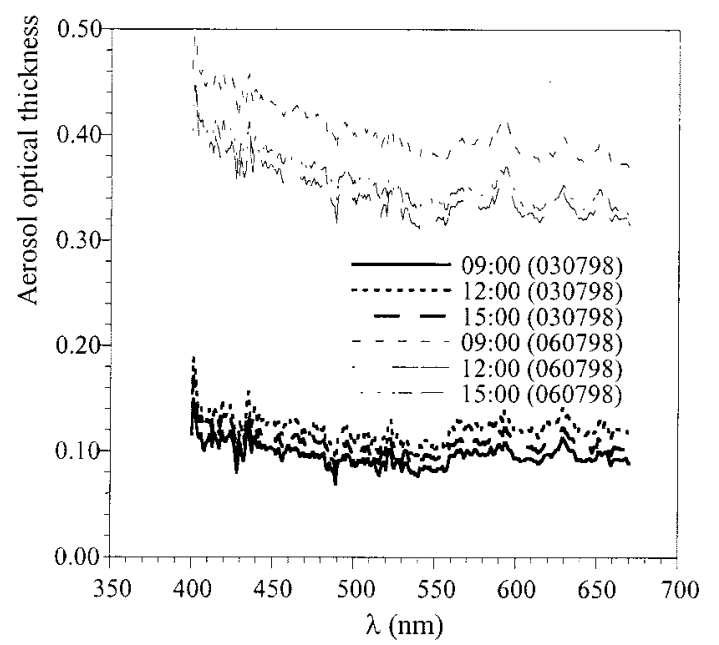

(b)

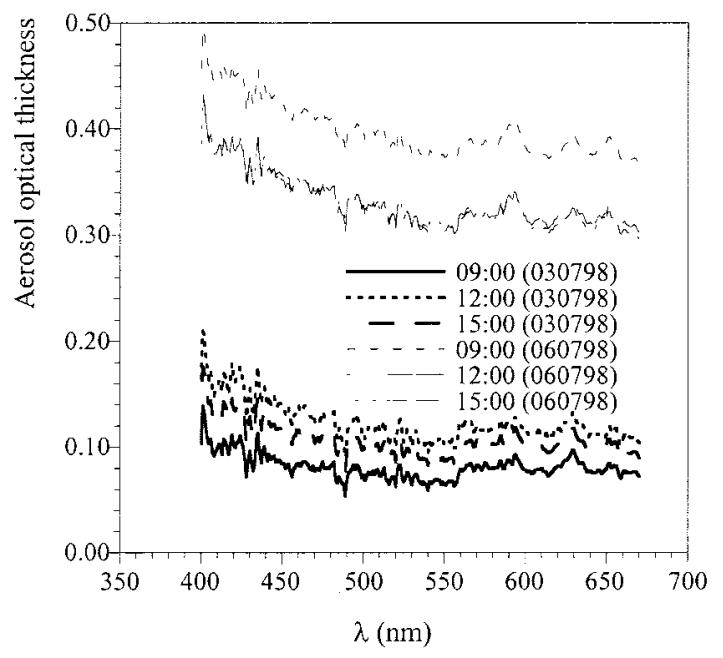

(c)

Fig. 4. Spectral aerosol optical thickness in the 400-670 nm range at 9:00, 12:00, and 15:00 TST: (a) Valencia City Center; (b) Albufera Natural Park; and (c) Chulilla.

and $0.90-0.98$ (site 3 ) for July 6, 1998 (maritime wind conditions), and $0.80-0.95$ (site 1 ), $0.75-0.90$ (site 2 ) and $0.70-0.90$ (site 3) for July 3, 1998 (continental wind conditions). On the

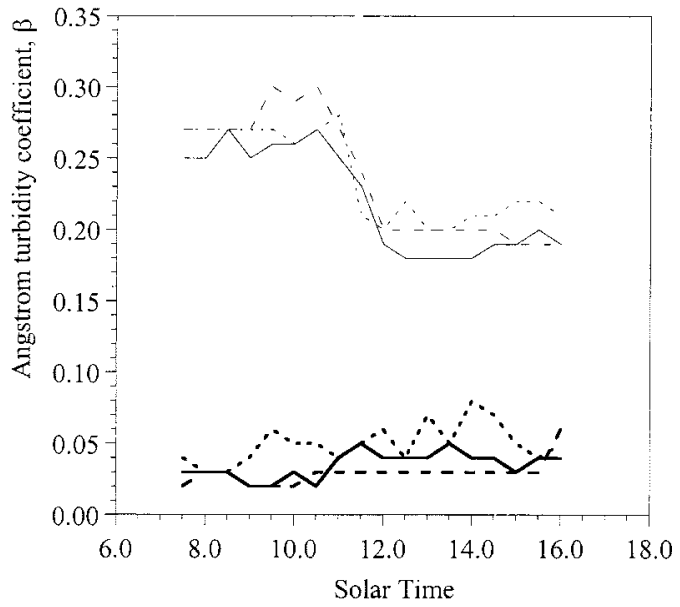

Fig. 5. Daily evolution of the Angstrom turbidity coefficient ( $\beta$ ) obtained from measurements in the 400-550 nm spectral range. (-) Valencia City Center, July 6, 1998; (...) Albufera Natural Park, July 6, 1998; (- - -) Chulilla, July 6, 1998; (-) Valencia City Center, July 3, 1998; (...) Albufera Natural Park, July 3, 1998; and (- - ) Chulilla, July 3, 1998.

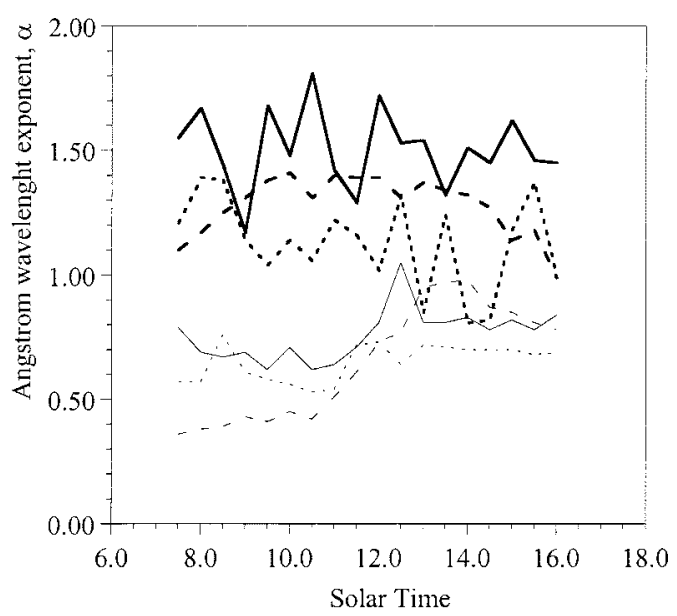

Fig. 6. Daily evolution of the Angstrom exponent $(\alpha)$ obtained from measurements in the 400-550 nm spectral range (-) Valencia City Center, July 6, 1998; (...) Albufera Natural Park, July 6, 1998; (- - ) Chulilla, July 6, 1998; (-) Valencia City Center, July 3, 1998; (...) Albufera Natural Park, July 3, 1998; and (- -) Chulilla, July 3, 1998.

other hand, in the spectral subinterval $550-670 \mathrm{~nm}$ the correlation coefficient $(r)$ values fall in the range $0.15-0.55$ (site 1 ), $0.15-0.70$ (site 2), and 0.05-0.65 (site 3) for July 6, 1998, and $0.05-0.45$ (site 1 ), $0.05-0.25$ (site 2 ), and $0.15-0.55$ (site 3 ) for July 3, 1998. These results indicate clearly that in the longer wavelength range the correlations were much lower. This agrees with the results of Reid et al. [44], who have recently demonstrated, using measurements made with a CIMEL 8 band sunphotometer with the same spectral range as the LICOR spectroradiometer, that the correlation coefficient between $\alpha$ and the size parameters decreases rapidly as the wavelength interval used for computing $\alpha$ included longer wavelengths. When the analysis includes the higher wavelengths available from the CIMEL there is no longer any statistically significant relationship between $\alpha$ and the particle size parameters. In view of these results, we have analyzed only the curves in the $400-550 \mathrm{~nm}$ wavelength range. In this spectral range, for the 
TABLE III

COEFFicients of THE SECOND-ORder POlynOMial $\ln \tau_{a}=a_{0}+a_{1} \ln \lambda+a_{2}(\ln \lambda)^{2}$ IN THE $400-670$ nm SPECTRAL RANGE FOR JUly 6, 1998. 1) VAlencia City Center; 2) Albufera Natural Park; AND 3) Chulilla

\begin{tabular}{|c|c|c|c|c|c|c|c|c|c|c|c|c|}
\hline \multirow{2}{*}{$\begin{array}{l}\text { Solar } \\
\text { Time }\end{array}$} & \multicolumn{4}{|c|}{ Site 1} & \multicolumn{4}{|c|}{ Site 2} & \multicolumn{4}{|c|}{ Site 3} \\
\hline & $a_{0}$ & $a_{1}$ & $a_{2}$ & r & $\mathrm{a}_{0}$ & $\mathrm{a}_{1}$ & $a_{2}$ & $r$ & $a_{0}$ & $a_{1}$ & $\mathrm{a}_{2}$ & $\mathrm{r}$ \\
\hline $7: 30$ & -0.82 & 0.71 & 0.96 & 0.98 & -0.84 & 0.63 & 0.76 & 0.95 & -0.88 & 0.73 & 0.69 & 0.84 \\
\hline $8: 00$ & -0.75 & 0.89 & 1.00 & 0.96 & -0.82 & 0.71 & $0.8 I$ & 0.94 & -0.85 & 0.85 & 0.79 & 0.83 \\
\hline $8: 30$ & -0.73 & 0.84 & 0.96 & 0.96 & -0.81 & 0.57 & 0.85 & 0.97 & -0.79 & 0.93 & 0.84 & 0.82 \\
\hline $9: 00$ & -0.66 & 1.22 & 1.21 & 0.94 & -0.79 & 0.77 & 0.87 & 0.94 & -0.75 & 0.96 & 0.88 & 0.85 \\
\hline $9: 30$ & -0.70 & 1.00 & 1.03 & 0.93 & -0.74 & 0.93 & 0.95 & 0.91 & -0.67 & 0.98 & 0.88 & 0.83 \\
\hline $10: 00$ & -0.66 & 1.05 & 1.12 & 0.95 & -0.72 & 1.02 & 1.00 & 0.89 & -0.65 & 1.03 & 0.94 & 0.85 \\
\hline $10: 30$ & -0.64 & 1.08 & 1.08 & 0.92 & -0.71 & 0.97 & 0.95 & 0.88 & -0.63 & 1.08 & 0.96 & 0.82 \\
\hline $11: 00$ & -0.68 & 1.23 & 1.19 & 0.90 & -0.68 & 1.00 & 0.97 & 0.87 & -0.68 & 1.13 & 1.04 & 0.86 \\
\hline $11: 30$ & -0.68 & 1.34 & 1.30 & 0.92 & -0.78 & 1.28 & 1.27 & 0.90 & -0.70 & 1.27 & 1.19 & 0.89 \\
\hline $12: 00$ & -0.74 & 1.62 & 1.55 & 0.92 & -0.78 & 1.31 & 1.29 & 0.90 & -0.80 & 1.33 & 1.31 & 0.92 \\
\hline $12: 30$ & -1.07 & 0.69 & 1.13 & 0.96 & -0.81 & 1.19 & 1.15 & 0.87 & -0.82 & 1.25 & 1.28 & 0.93 \\
\hline $13: 00$ & -0.78 & 1.60 & 1.53 & 0.91 & -0.82 & 1.36 & 1.31 & 0.89 & -0.84 & 0.99 & 1.24 & 0.97 \\
\hline $13: 30$ & -0.79 & 1.56 & 1.51 & 0.92 & -0.84 & 1.26 & 1.24 & 0.89 & -0.82 & 1.04 & 1.28 & 0.97 \\
\hline $14: 00$ & -0.82 & 1.46 & 1.45 & 0.93 & -0.83 & 1.20 & 1.19 & 0.90 & -0.87 & 0.89 & 1.19 & 0.97 \\
\hline $14: 30$ & -0.99 & 0.97 & 1.09 & 0.93 & -0.83 & 1.13 & 1.16 & 0.91 & -0.92 & 0.90 & 1.13 & 0.96 \\
\hline $15: 00$ & -0.87 & 1.26 & 1.32 & 0.94 & -0.85 & 0.99 & 1.07 & 0.93 & -0.94 & 1.04 & 1.20 & 0.96 \\
\hline $15: 30$ & -0.90 & 1.10 & 1.20 & 0.94 & -0.87 & 0.93 & 1.01 & 0.93 & -0.96 & 1.01 & 1.16 & 0.96 \\
\hline $16: 00$ & -0.96 & 0.95 & 1.13 & 0.96 & -0.93 & 0.87 & 0.98 & 0.93 & -1.00 & 0.87 & 1.05 & 0.96 \\
\hline
\end{tabular}

TABLE IV

COEFFicients of the SeCOND-ORder POLYNOMIAL $\ln \tau_{a}=a_{0}+a_{1} \ln \lambda+a_{2}(\ln \lambda)^{2}$ IN THE $400-670 \mathrm{~nm}$ SPECTRAL RANGE FOR JUly 3, 1998. 1) VAlencia City Center; 2) Albufera Natural Park; AND 3) Chulilla

\begin{tabular}{|c|c|c|c|c|c|c|c|c|c|c|c|c|}
\hline \multirow{2}{*}{$\begin{array}{l}\text { Solar } \\
\text { Time } \\
\end{array}$} & \multicolumn{4}{|c|}{ Site 1} & \multicolumn{4}{|c|}{ Site 2} & \multicolumn{4}{|c|}{ Site 3} \\
\hline & $\mathrm{a}_{0}$ & $a_{1}$ & $a_{2}$ & $\mathrm{r}$ & $a_{0}$ & $a_{1}$ & $a_{2}$ & $\mathrm{r}$ & $a_{0}$ & $a_{1}$ & $a_{2}$ & $r$ \\
\hline $7: 30$ & -1.55 & 3.79 & 3.35 & 0.82 & -1.60 & 3.07 & 2.67 & 0.76 & -1.56 & 4.53 & 3.51 & 0.57 \\
\hline $8: 00$ & -1.56 & 3.19 & 3.06 & 0.91 & -1.47 & 3.60 & 3.10 & 0.76 & -1.42 & 4.62 & 3.63 & 0.61 \\
\hline $8: 30$ & -1.18 & 4.49 & 3.70 & 0.74 & -1.43 & 3.69 & 3.15 & 0.73 & -1.28 & 4.89 & 3.87 & 0.64 \\
\hline $9: 00$ & -1.17 & 4.79 & 3.98 & 0.73 & -1.38 & 3.40 & 2.81 & 0.65 & -1.12 & 5.34 & 4.19 & 0.63 \\
\hline $9: 30$ & -1.09 & 5.25 & 4.31 & 0.70 & -1.34 & 2.88 & 2.43 & 0.69 & -0.98 & 5.68 & 4.45 & 0.65 \\
\hline $10: 00$ & -0.57 & 6.15 & 4.77 & 0.70 & -1.34 & 2.87 & 2.48 & 0.72 & -0.94 & 5.71 & 4.49 & 0.65 \\
\hline $10: 30$ & -1.01 & 5.13 & 4.32 & 0.76 & -1.32 & 3.14 & 2.58 & 0.59 & -0.86 & 5.81 & 4.47 & 0.63 \\
\hline $11: 00$ & -0.60 & 5.49 & 4.33 & 0.72 & -1.31 & 3.40 & 2.85 & 0.63 & -0.73 & 6.15 & 4.76 & 0.65 \\
\hline $11: 30$ & -0.69 & 4.74 & 3.78 & 0.73 & -1.24 & 3.32 & 2.76 & 0.63 & -0.78 & 5.92 & 4.59 & 0.64 \\
\hline $12: 00$ & -1.19 & 3.71 & 3.40 & 0.86 & -1.09 & 3.47 & 2.77 & 0.60 & -0.80 & 5.69 & 4.45 & 0.65 \\
\hline $12: 30$ & -1.11 & 3.64 & 3.25 & 0.84 & -1.11 & 3.93 & 3.27 & 0.68 & -0.81 & 5.62 & 4.35 & 0.64 \\
\hline $13: 00$ & -1.05 & 3.88 & 3.40 & 0.83 & -1.05 & 3.14 & 2.48 & 0.58 & -0.86 & 5.21 & 4.12 & 0.67 \\
\hline $13: 30$ & -0.99 & 3.99 & 3.30 & 0.72 & -1.22 & 3.46 & $2.9 \mathrm{I}$ & 0.68 & -0.94 & 5.05 & 4.01 & 0.67 \\
\hline $14: 00$ & -1.21 & 3.85 & 3.34 & 0.79 & -1.13 & 2.87 & 2.28 & 0.58 & -0.93 & 5.27 & 4.13 & 0.65 \\
\hline $14: 30$ & -1.11 & 3.99 & 3.40 & 0.79 & -1.16 & 2.91 & 2.30 & 0.58 & -1.09 & 4.90 & 3.85 & 0.63 \\
\hline $15: 00$ & -1.20 & 4.01 & 3.52 & 0.82 & -1.29 & 3.35 & 2.80 & 0.68 & -1.18 & 4.77 & 3.69 & 0.60 \\
\hline $15: 30$ & -1.33 & 3.48 & 3.09 & 0.82 & -1.49 & 3.09 & 2.76 & 0.78 & -1.37 & 3.89 & 3.18 & 0.68 \\
\hline $16: 00$ & -1.50 & 3.08 & 2.83 & 0.85 & -1.46 & 2.69 & 2.28 & 0.68 & -1.42 & 2.76 & 2.36 & 0.75 \\
\hline
\end{tabular}

three measurement stations, the daily evolution of the turbidity coefficient $\beta$ values (Fig. 5) varied between 0.18 and 0.30 for July 6, 1998 and between 0.02 and 0.08 for July 3, 1998. For average turbidity conditions they showed a similar evolution during the day, with a tendency to decrease in the afternoon in the case of maritime wind conditions. This coincides with previous results obtained for the area of Valencia from measurements of wide band solar radiation which show that the morning turbidity values are higher than the afternoon ones [42].

The daily evolution of the Angstrom exponent $\alpha$ in this spectral range is shown in Fig. 6. Under maritime wind conditions (July 6, 1998) it can be seen that at the sites close to the coast ( 1 and 2) the value of $\alpha$ is fairly stable with values between 0.60 and 0.80 which suggests that the aerosol size distribution remains more or less the same (at least the basic shape). The observed values of $\alpha$ are those of a coastal site subject to mar- itime winds [50]. For site 3 the values of $\alpha$ evolved more during the day passing from values close to 0.40 early in the morning to around $0.80-0.90$ in the afternoon. This seems to indicate a change in the aerosol characteristics present at this site with a decrease in their size through the day until they reached values similar to those found on the coast. One possible explanation could be that there was fog or high morning clouds, but neither was seen during the measurement campaign. It makes sense that cooler morning temperatures increase relative humidity causing larger particles. As the temperature increases during the day relative humidity decreases and the same particles lose water and shrink. Diurnal temperatures differences are more pronounced inland than along the coast.

Under continental wind conditions (July 3, 1998), the values of $\alpha$ at the three measurement sites were noticeably higher than for the other days, when there were maritime winds, sometimes higher by a factor of two. In these conditions, the average values 
TABLE V

COEFFicients OF THE SECOND-ORder POLYNOMIAL FIT $\ln \tau_{a}=a_{0}+a_{1} \ln \lambda+a_{2}(\ln \lambda)^{2}$ IN THE 400-550 nm SPECTRAL RANGE FOR JULY 6, 1998. 1) Valencia City Center; 2) Albufera Natural Park; and 3) Chulilla

\begin{tabular}{|c|c|c|c|c|c|c|c|c|c|c|c|c|}
\hline \multirow{2}{*}{$\begin{array}{l}\text { Solar } \\
\text { Time }\end{array}$} & \multicolumn{4}{|c|}{ Site 1} & \multicolumn{4}{|c|}{ Site 2} & \multicolumn{4}{|c|}{ Site 3} \\
\hline & $\mathrm{a}_{0}$ & $a_{1}$ & $\mathrm{a}_{2}$ & $r$ & $\mathrm{a}_{0}$ & $a_{1}$ & $a_{2}$ & $\mathrm{r}$ & $\mathrm{a}_{0}$ & $a_{1}$ & $\mathrm{a}_{2}$ & $\mathrm{r}$ \\
\hline $7: 30$ & -1.11 & -0.03 & 0.36 & 0.97 & -1.11 & -0.03 & 0.36 & 0.97 & -1.13 & 0.09 & 0.30 & 0.93 \\
\hline $8: 00$ & -1.09 & 0.03 & 0.40 & 0.97 & -1.09 & 0.03 & 0.40 & 0.97 & -1.12 & 0.17 & 0.37 & 0.92 \\
\hline $8: 30$ & -1.20 & -0.43 & 0.22 & 0.98 & -1.20 & -0.43 & 0.22 & 0.98 & -1.04 & 0.33 & 0.47 & 0.90 \\
\hline $9: 00$ & -1.13 & -0.07 & 0.35 & 0.96 & -1.13 & -0.07 & 0.35 & 0.96 & -0.99 & 0.38 & 0.54 & 0.92 \\
\hline $9: 30$ & -1.15 & -0.12 & 0.31 & 0.94 & -1.15 & -0.12 & 0.31 & 0.94 & -0.93 & 0.36 & 0.51 & 0.91 \\
\hline $10: 00$ & -1.14 & -0.03 & 0.35 & 0.93 & -1.14 & -0.03 & 0.35 & 0.93 & -0.85 & 0.57 & 0.67 & 0.91 \\
\hline $10: 30$ & -1.11 & -0.03 & 0.33 & 0.92 & -1.11 & -0.03 & 0.33 & 0.92 & -0.85 & 0.55 & 0.64 & 0.89 \\
\hline $11: 00$ & -1.02 & 0.15 & 0.45 & 0.91 & -1.02 & 0.15 & 0.45 & 0.91 & -0.97 & 0.43 & 0.62 & 0.91 \\
\hline $11: 30$ & -1.28 & 0.03 & 0.49 & 0.93 & -1.28 & 0.03 & 0.49 & 0.93 & -1.00 & 0.53 & 0.75 & 0.93 \\
\hline $12: 00$ & -1.37 & -0.16 & 0.38 & 0.93 & -1.37 & -0.16 & 0.38 & 0.93 & -1.17 & 0.40 & 0.74 & 0.94 \\
\hline $12: 30$ & -1.35 & -0.17 & 0.31 & 0.91 & -1.35 & -0.17 & 0.31 & 0.91 & -1.15 & 0.44 & 0.79 & 0.95 \\
\hline $13: 00$ & -1.40 & -0.09 & 0.41 & 0.93 & -1.40 & -0.09 & 0.41 & 0.93 & -1.25 & -0.03 & 0.60 & 0.98 \\
\hline $13: 30$ & -1.39 & -0.10 & 0.40 & 0.93 & -1.39 & -0.10 & 0.40 & 0.93 & -1.25 & -0.02 & 0.62 & 0.98 \\
\hline $14: 00$ & -1.37 & -0.16 & 0.35 & 0.94 & -1.37 & -0.16 & 0.35 & 0.94 & -1.24 & -0.03 & 0.63 & 0.98 \\
\hline $14: 30$ & -1.23 & 0.15 & 0.56 & 0.94 & -1.23 & 0.15 & 0.56 & 0.94 & -1.29 & -0.03 & 0.55 & 0.97 \\
\hline $15: 00$ & -1.27 & -0.05 & 0.43 & 0.95 & -1.27 & -0.05 & 0.43 & 0.95 & -1.35 & 0.01 & 0.56 & 0.97 \\
\hline $15: 30$ & -1.25 & -0.00 & 0.45 & 0.96 & -1.25 & -0.00 & 0.45 & 0.96 & -1.34 & 0.07 & 0.58 & 0.97 \\
\hline $16: 00$ & -1.25 & 0.08 & 0.50 & 0.97 & -1.25 & 0.08 & 0.50 & 0.97 & -1.40 & -0.14 & 0.43 & 0.98 \\
\hline
\end{tabular}

TABLE VI

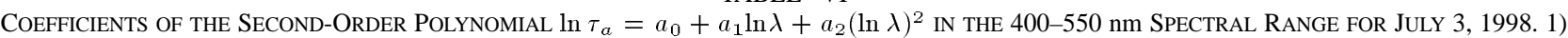
Valencia City Center; 2) Albufera Natural Park; AND 3) ChuliLla

\begin{tabular}{|c|c|c|c|c|c|c|c|c|c|c|c|c|}
\hline \multirow{2}{*}{$\begin{array}{l}\text { Solar } \\
\text { Time }\end{array}$} & \multicolumn{4}{|c|}{ Site 1} & \multicolumn{4}{|c|}{ Site 2} & \multicolumn{4}{|c|}{ Site 3} \\
\hline & $\mathrm{a}_{0}$ & $a_{1}$ & $\mathrm{a}_{2}$ & $\mathrm{r}$ & $\mathrm{a}_{0}$ & $\mathrm{a}_{1}$ & $\mathrm{a}_{2}$ & $r$ & $\mathrm{a}_{0}$ & $a_{1}$ & $a_{2}$ & $r$ \\
\hline $7: 30$ & -2.90 & 0.45 & 1.31 & 0.93 & -2.46 & 1.02 & 1.46 & 0.91 & -2.86 & 1.38 & 1.61 & 0.74 \\
\hline $8: 00$ & -2.75 & 0.23 & 1.24 & 0.95 & -2.40 & 1.42 & 1.83 & 0.90 & -2.67 & 1.56 & 1.77 & 0.76 \\
\hline $8: 30$ & -1.87 & 2.96 & 2.87 & 0.88 & -2.67 & 0.70 & 1.36 & 0.88 & -2.56 & 1.72 & 1.93 & 0.77 \\
\hline $9: 00$ & -1.95 & 3.06 & 3.05 & 0.87 & -2.41 & 0.95 & 1.36 & 0.82 & -2.59 & 1.69 & 1.95 & 0.75 \\
\hline $9: 30$ & -2.23 & 2.57 & 2.77 & 0.84 & -2.24 & 0.73 & 1.16 & 0.84 & -2.21 & 2.68 & 2.65 & 0.76 \\
\hline $10: 00$ & -1.32 & 4.52 & 3.91 & 0.81 & -2.40 & 0.29 & 0.93 & 0.85 & -2.43 & 2.03 & 2.23 & 0.75 \\
\hline $10: 30$ & -1.86 & 3.22 & 3.27 & 0.87 & -2.73 & -0.30 & 0.48 & 0.77 & -1.86 & 3.47 & 3.11 & 0.70 \\
\hline $11: 00$ & -1.23 & 4.12 & 3.62 & 0.84 & -2.68 & 0.07 & 0.83 & 0.79 & -2.13 & 2.74 & 2.69 & 0.72 \\
\hline $11: 30$ & -1.23 & 3.59 & 3.19 & 0.86 & -2.89 & -0.78 & 0.23 & 0.79 & -1.98 & 3.04 & 2.88 & 0.73 \\
\hline $12: 00$ & -2.11 & 1.53 & 2.12 & 0.92 & -2.37 & 0.34 & 0.88 & 0.76 & -2.15 & 2.39 & 2.46 & 0.75 \\
\hline $12: 30$ & -1.98 & 1.55 & 2.01 & 0.91 & -2.74 & -0.10 & 0.79 & 0.82 & -1.88 & 3.09 & 2.87 & 0.72 \\
\hline $13: 00$ & -1.93 & 1.77 & 2.16 & 0.91 & -1.99 & 0.90 & 1.15 & 0.74 & -1.78 & 3.06 & 2.89 & 0.79 \\
\hline $13: 30$ & -1.51 & 2.93 & 2.77 & 0.87 & -2.65 & -0.07 & 0.76 & 0.83 & -2.14 & 2.13 & 2.26 & 0.79 \\
\hline 14.00 & -1.97 & 2.09 & 2.35 & 0.89 & -1.97 & 0.87 & 1.10 & 0.76 & -2.32 & 1.89 & 2.09 & 0.76 \\
\hline $14: 30$ & -1.77 & 2.50 & 2.58 & 0.90 & -1.94 & 1.08 & 1.25 & 0.76 & -2.25 & 2.11 & 2.20 & 0.76 \\
\hline $15: 00$ & -1.95 & 2.30 & 2.56 & 0.92 & -2.11 & 1.46 & 1.72 & 0.84 & -1.68 & 3.72 & 3.18 & 0.72 \\
\hline $15: 30$ & -2.20 & 1.42 & 1.88 & 0.92 & -2.68 & 0.22 & 1.04 & 0.89 & -2.37 & 1.49 & 1.75 & 0.82 \\
\hline $16: 00$ & -2.20 & 1.45 & 1.90 & 0.93 & -2.28 & 0.75 & 1.15 & 0.86 & -2.27 & 0.68 & 1.10 & 0.88 \\
\hline
\end{tabular}

for $\alpha$ were similar at all three sites, ranging between 1.10 and 1.50. It is worth noting that they were most stable at site 3 (rural), possibly due to its distance from the coast and the industrial areas around the city of Valencia, to the east. The values of $\alpha$ for this day indicate the presence of smaller aerosols, presumably of continental origin, compared with the mainly maritime aerosols detected in July 6, 1998.

Recently Eck et al. [15] have proposed using a second-order polynomial fit of the form

$$
\ln \tau_{a}=a_{0}+a_{1} \ln _{\lambda}+a_{2}(\ln \lambda)^{2}
$$

to account the curvature in the $\ln \tau_{a}$ versus $\ln _{\lambda}$, found in the results obtained from measurements made with sunphotometers. They propose using, as a parameter to quantify the curvature, the second derivative of $\ln \tau_{a}$ versus $\ln _{\lambda}$, which is the same as the derivative of $\alpha$ with respect to $\ln \lambda$. According to them, a positive curvature is indicative of the dominance of accumulation mode sized particles in the volume size distribution and the addition of coarse particles to the size distribution results in a marked decrease in curvature [15].

We made adjustments in this way, both for the full spectral range 400-670 nm (Tables III and IV) and in the shorter wavelength range 400-550 $\mathrm{nm}$ (Tables V and VI). When the whole range is used, the correlation improves noticeably, particularly for July 3, 1998 (Table IV). However when the adjustment is applied to the $400-550 \mathrm{~nm}$ range, the correlation coefficients hardly change, indicating that the Angstrom approximation given by (4) is sufficient in this wavelength range. Nevertheless, we have analyzed the curves of this spectral range, shown in the tables as the coefficient $a_{2}$, in order to determine whether it was possible to detect differences in the types of aerosols from this coefficient. When there was a maritime wind (July 6, 1998, Table V), the average values of $a_{2}$ were very small, around 0.40 , 
at all three sites. When there was a continental wind (July 3 , 1998, Table VI), the average values were around 1.1 at site 2 and 2.5 at sites 1 and 3 . Since the way in which we made the adjustment means that a positive coefficient indicates negative curvature, then in accordance with the conclusions of Eck et al. [15], under maritime wind conditions, we would have a quite uniform mix of accumulation and coarse mode sized particles, which would give almost no curvature. Meanwhile, the markedly negative curvature would indicate a clear predominance of coarse particles in the size distribution. This predominance would be noticeably less at site 2, the Albufera Natural Park, located close to the coast.

\section{Aerosol Size Distribution}

The determination of the size distribution of the atmospheric aerosol from extinction measurements can be formulated in terms of a Fredholm integral equation of the first kind [61]. The aerosol size distribution can be obtained from the shape of the AOT curve $\tau_{a \lambda}$, solving the integral

$$
\tau_{a \lambda}=\int_{0}^{\infty} \pi r^{2} Q\left(r, \lambda, m_{r}\right) n_{c}(r) d r
$$

where

$$
\begin{aligned}
& Q\left(r, \lambda, m_{r}\right) \\
& m_{r} \\
& n_{c}(r) .
\end{aligned}
$$

Mie theory extinction efficiency factor; complex refractive index; aerosol size distribution, which corresponds to the number of particles per unit radius interval per unit area in a vertical column through the atmosphere.

The inversion of (6) is an example of an ill-posed problem, where $Q\left(r, \lambda, m_{r}\right)$ is the kernel, and $n_{c}(r)$ is the unknown function to determine. Over the years, a number of techniques have been employed to solve this inversion [5], including constrained linear, iterative, analytic, singular function theory, empirical orthogonal functions, and analytic eigenfunction theory.

We have employed the method proposed by King et al. [28], [29], which has been previously employed by other investigators to calculate the aerosol size distribution [18], [39], [51], [53], [54], [38]. To guarantee the convergence of the method, it is very important to choose properly the radii interval where the equation is going to be applied. Here all the inversions were performed assuming for the integral limits the 0.05 to $4.0 \mu \mathrm{m}$ radii values, and using nine wave bands of equal relative weight. For all the inversions, we considered that the complex refractive index of the aerosol particles is both wavelength and size independent [37]. To test the validity of the results, from the obtained distribution functions, the spectral AOT was reconstructed using (6). The experimental values of AOT and those obtained from (6) were compared using the root mean square deviation (RMSD).

The size distributions obtained in this way were, in general, quite similar although there were some specific characteristics for different days. For July 6, 1998, they were practically constant throughout the day, with the shape shown in Fig. 7, which corresponds to 12:00 TST. They have a clear bimodal form, although in the curve shown the position of the separation of the two modes is not very marked. They are practically the same for the three sites, which corroborates the supposition that on

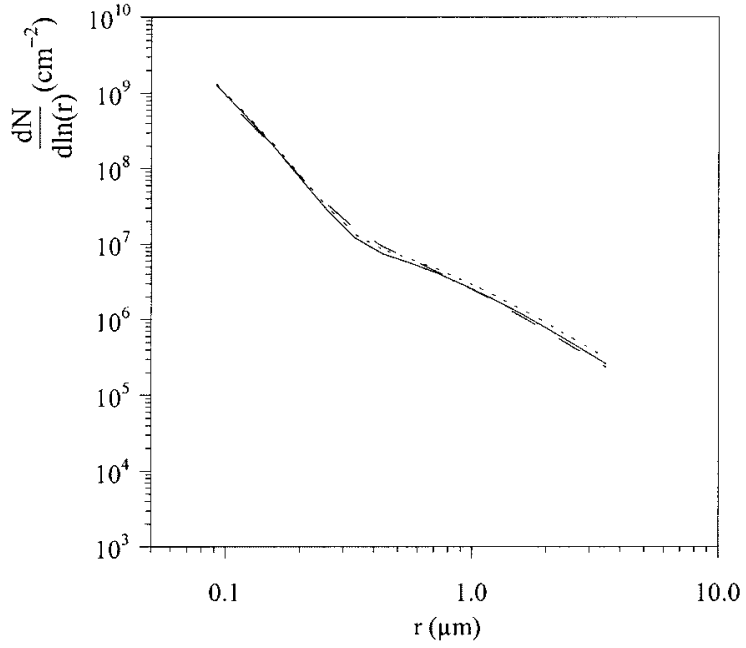

Fig. 7. Particle size distribution obtained from extinction spectral measurements at (...) Valencia City Center; (- - ) Albufera Natural Park;and (一) Chulilla. July 6, 1998, 12:00 TST

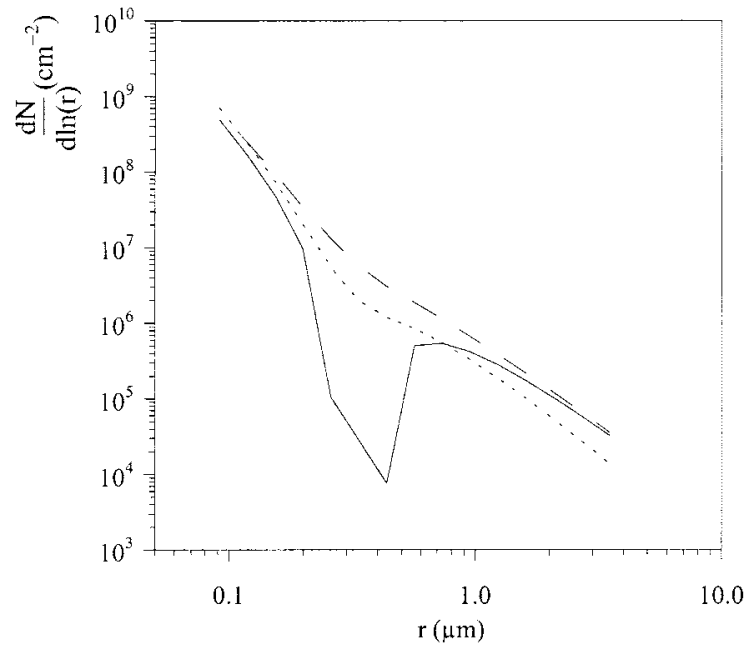

Fig. 8. Particle size distribution obtained from extinction spectral measurements at (...) Valencia City Center; (- - -) Albufera Natural Park; and (一) Chulilla. July 3, 1998, 10:00 TST.

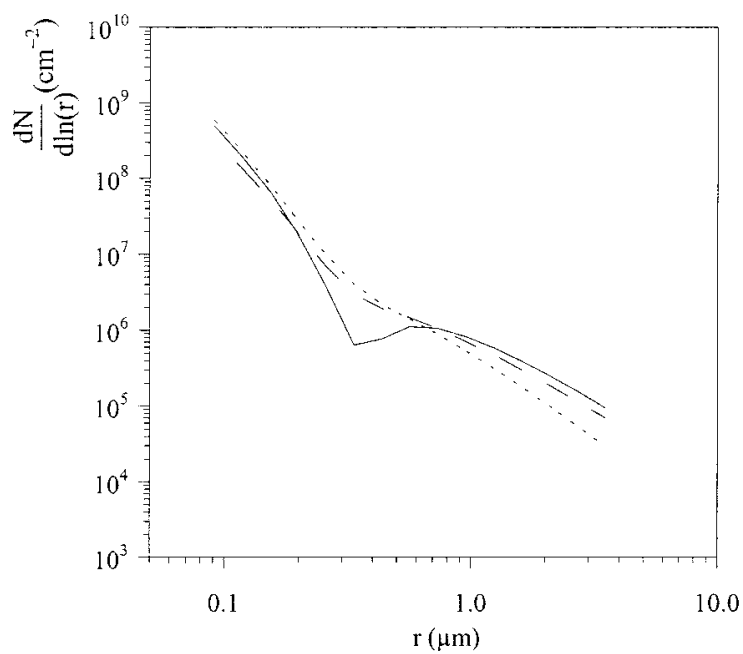

Fig. 9. Particle size distribution obtained from extinction spectral measurements at $(\ldots)$ Valencia City Center; (- - ) Albufera Natural Park; and (一) Chulilla. July 3, 1998, 16:00 TST. 


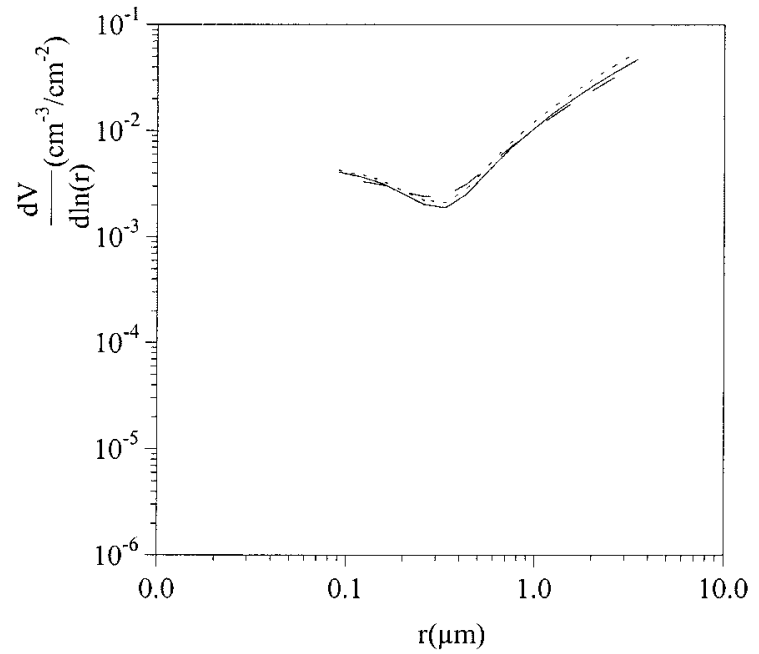

(a)

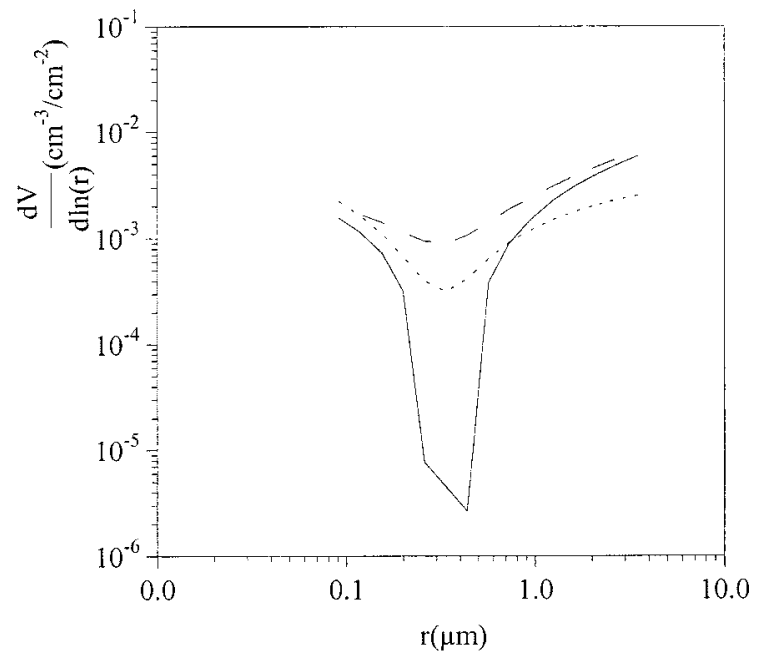

(b)

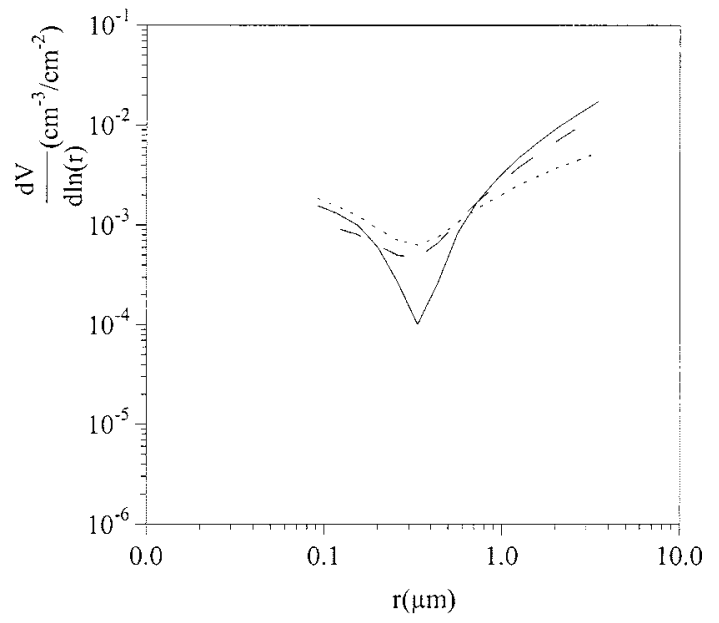

(c)

Fig. 10. Volume size distribution at (...) Valencia City Center; (- - -) Albufera Natural Park; (-) Chulilla. a) July 6, 1998, 12:00 TST; b) July 3, 1998, 10:00 TST; and c) July 3, 1998, 16:00 TST.

clear days with a maritime wind the effect is to make the atmosphere very uniform over the whole of the area studied. The AOT values obtained from these curves shows some small de- viations with respect to the experimental AOT values with an RMSD lower than $2 \%$ for the whole of the spectral range.

For July 3, 1998, the size distribution curves showed a marked evolution through the day. Figs. 8 and 9 show the curves for 10:00 and 16:00 TST. It can be seen that while the shape of the curves for the sites close to the sea, (1-Valencia City Center, 2-Albufera National Park) are very similar to those for July 6, 1998, at site 3 (rural) the inflection point that shows the bimodal character of the curve is much more accentuated, especially for the measurements made during the morning. For this day, the deviations of the AOT values derived from (6) relative to the experimental values are significantly higher with an RMSD between $5 \%$ and $8 \%$ at $16: 00$ TST and between $5 \%$ and $25 \%$ at 10:00 TST. The latter value was atypical and corresponded to the Valencia City Center measurement station, suggesting that the inversions from this station during that morning should be used with caution.

To make the bimodal nature of the obtained size distributions more visible, we show in Fig. 10 the plot of volume against radius. It can be seen that, in general, all the size distributions have common features with a saddle point at $0.34 \mu \mathrm{m}$. This value is lower than those obtained by Higurashi and Nakajima [21], Remer and Kaufman [45], and Remer et al. [46] from inversions of almucantar sky radiance measurements, which vary between $0.60 \mu \mathrm{m}$ and $0.80 \mu \mathrm{m}$, which could be due to differences in the nature of aerosols at the different locations. Only the size distributions for site 3 (rural) for the morning of July 3, 1998 (continental wind) show a displacement of this point up to a maximum of $0.44 \mu \mathrm{m}$. This value corresponded to the measurements with the lowest Angstrom exponent, which corroborates the presence of particles with greater radii. The curves do not allow the positions of the accumulation mode and the coarse mode to be observed. This is due to the radius range chosen for the inversion, imposed by the narrow wavelength range with which we were working. With a broader wavelength range, better definition of the modes could probably be obtained. Other authors [45], [46] have found similar limitations, but due to different causes. They observe the modes only when the AOT values at $670 \mathrm{~nm}$ are more than 0.4 , but due to the edge effects of the Nakajima angular inversion. This problem can be avoided in the new Dubovik inversion [13], [14], which is able to retrieve complete modes regardless of AOT.

\section{SUMMARY AND CONCLUSIONS}

Ground-based measurements using three Li-cor 1800 spectroradiometers were taken simultaneously at three sites: rural continental, rural coastal and urban coastal, during a field campaign from June 22 to July 10, 1998, in order to analyze AOT for typical synoptic summer conditions in Valencia, an urban coastal Mediterranean area. The results show the great dependence of the optical aerosol characteristic on the dominant winds (eastern maritime or western continental) in this area. When the continental wind predominates, the atmospheric conditions are those of very clear skies (AOT at $500 \mathrm{~nm}$ less than 0.2), while when maritime winds occur (the most frequent situation in the study area during summer), the conditions are those of a moderately turbid sky (AOT at $500 \mathrm{~nm}$ between 0.35 and 0.45 ). 
The curves of spectral aerosol optical thickness showed that for maritime winds, the AOT values were much higher than when continental winds occurred and that the slope of the curve of AOT wavelength was more pronounced in the former case. The values of the Angstrom exponent $\alpha$, when sea winds predominate, stayed the same throughout the day at sites near the coast, while at $50 \mathrm{~km}$ inland in a rural environment, they changed markedly, doubling in value during the day until reaching the same values as found on the coast during the afternoon. With a continental wind, the values of $\alpha$ at the three measurement sites were noticeably higher (practically double) than those found for the case of maritime winds, which indicates the presence of smaller sized aerosols of continental origin. The analysis of the curvature, proposed by Eck et al. [15] for the AOT spectral values, indicated a fairly uniform mix of accumulation and coarse mode sized particles under maritime wind conditions. Under continental wind conditions, the markedly negative curvature indicated a clear predominance of coarse particles in the size distribution.

The aerosol size distributions curves were bimodal in every case. For maritime wind conditions, they stayed practically constant throughout the day and had the same characteristics at all three sites. When the wind blew from the sea, this factor prevailed over all others and determined the type of aerosols present over the whole of the area. With continental winds, the size distributions were the same as the previous ones only for the sites close to the coast. In these cases, all the size distributions had common features with a saddle point at $0.34 \mu \mathrm{m}$. However, at the measurement station (classified as rural) with a continental wind, the bimodal character of the distribution was more accentuated and the saddle point was displaced to $0.44 \mu \mathrm{m}$, indicating the presence of larger particles.

In general, we can say that for synoptic summer conditions for which the predominant wind is from the east (maritime), the aerosols are smaller and have similar characteristics over the whole of the area studied. However, for conditions where winds from the west (rural-continental) predominate, it is possible to distinguish between the aerosol types present at the coast and points located $50 \mathrm{~km}$ inland. Finally, it should be noted that from the measurements made during this campaign, it was not possible to establish the influence of urban aerosols, which should have been detectable in the center of the city of Valencia. We hope that in future measurement campaigns, it will be possible to measure sky radiance and so establish this influence based on parameters that have not been analyzed in this case, in particular the phase angle and the asymmetry parameter.

\section{REFERENCES}

[1] S. M. Anderson and K. Mauersberger, "Measurements of ozone absorption cross section in the Chappuis band," Geophys. Res. Lett., vol. 19, pp. 933-936, 1992.

[2] A. Angstrom, "On the atmospheric transmission of sun radiation and on the dust in the air," Geografis. Annal., vol. 11, pp. 156-166, 1929.

[3] — , "On the atmospheric transmission of sun radiation," Geografis. Annal., vol. 12, pp. 130-159, 1930.

[4] B. A. Bodahine, N. B. Wood, E. G. Dutton, and J. R. Slusser, "On Rayleigh optical depth calculations," J. Atmos. Ocean. Technol., vol. 16, pp. 1854-1861, 1999.

[5] G. P. Box, K. M. Sealey, and M. A. Box, "Inversion of Mie extinction measurements using analytic eigenfunction theory," J. Atmos. Sci., vol. 49, pp. 2074-2081, 1992.
[6] V. E. Cachorro, A. M. De Frutos, and J. L. Casanovas, "Determination of the Angstrom turbidity parameters," Appl. Opt., vol. 26, pp. 3069-3076, 1987.

[7] V. E. Cachorro, M. J. Gonzalez, A. M. De Frutos, and J. L. Casanovas, "Fitting Angstrom formula to spectrally aerosol optical thickness," Atmos. Environ., vol. 23, pp. 265-270, 1989.

[8] V. E. Cachorro, M. P. Utrillas, R. Vergaz, P. Durán, A. M. De Frutos, and J. A. Martínez-Lozano, "An study about the water vapor content determination in the $940 \mathrm{~nm}$ band by using moderated spectral resolution measurements of direct solar irradiance," Appl. Opt., vol. 37, pp. 4678-4689, 1998.

[9] J. A. Davidson, C. A. Cantrell, A. H. McDaniel, R. E. Shetter, S. Madronich, and J. G. Calvert, "Visible-ultraviolet absorption cross sections for $\mathrm{NO}_{2}$ as a function of the temperature," J. Geophys. Res. vol. 93, pp. 7105-7112, 1988.

[10] J. P. Díaz, F. J. Expósito, C. J. Torres, V. Carreño, and A. Redondas, "Simulation of mineral dust effects on UV radiation levels," J. Geophys. Res., vol. 105, pp. 4979-4991, 2000.

[11] D. J. Diner, G. P. Asner, R. Davies, Y. Knyazikhin, J. P. Muller, A. W. Nolin, B. Pinty, C. S. Schaaf, and J. Stroeve, "New directions in the Earth observing: Scientific applications of multiangle remote sensing," Bull. Amer. Meteorol. Soc., vol. 80, pp. 2209-2228, 1999.

[12] E. G. Dutton, R. Patrick, S. Ryan, and J. J. DeLuisi, "Features and effects of aerosol optical depth observed at Mauna Loa, HI: 1982-1992," J. Geophys. Res., vol. 99, pp. 8295-8306, 1994.

[13] O. Dubovik and M. D. King, "A flexible inversion algorithm for retrieval of aerosol optical properties from sun and sky radiance measurements,' J. Geophys. Res., vol. 105, pp. 20673-20 696, 2000.

[14] O. Dubovik, A. Smirnov, and B. N. Holben et al., "Optical properties retrieved from aerosol robotic network (AERONET) sun and sky radiance measurements," J. Geophys. Res., vol. 105, pp. 9791-9806, 2000

[15] T. F. Eck, B. N. Holben, J. S. Reid, O. Dubovik, N. T. O’Neill, I. Slutsker, and S. Kinne, "Wavelength dependence of the optical depth of biomass burning, urban and desert dust aerosols," J. Geophys. Res., vol. 104, pp. 31 333-31349, 1999.

[16] Y. Fouquart and B. Bonnel, "Computation of solar heating of the earth's atmosphere: A new parameterization," Beitr. Phys. Atmos., vol. 53, pp. 35-62, 1980.

[17] Y. Fouquart, B. Bonnel, and V. Ramaswamy, "Intercomparing shortwave radiation codes for climate studies," J. Geophys. Res., vol. 96, pp 8955-8968, 1991

[18] H. Gonzalez and J. A. Ogren, "Sensitivity of retrieved aerosol properties to assumptions in the inversion of spectral optical depths," J. Atmos. Sci., vol. 53, pp. 3669-3685, 1997.

[19] M. C. Green, R. G. Flocchini, and L. O. Myrup, "The relationship of the extinction coefficient distribution to wind field patterns in Southern California," Atmos. Environ., vol. 26A, pp. 827-840, 1992.

[20] Tech. Rep. FSEC-PF-270-95, Florida Solar Energy Center, Cocoa, FL, 1995.

[21] A. Higurashi and T. Nakajima, "Development of a two-channel aerosol retrieval algorithm on a global scale using NOAA AVHRR," J. Atmos. Sci., vol. 56, pp. 924-941, 1999.

[22] N. N. Holben, A. Setzer, T. F. Eck, A. Pereira, and I. Slutsker, "Effect of dry season biomass burning on Amazon basin aerosol concentrations and optical properties," J. Geophys. Res., vol. 101, pp. 19455-19464, 1996.

[23] B. N. Holben, T. F. Eck, I. Slutsker, D. Tanré, J. P. Buis, A. Setzer, E. Vermote, J. A. Reagan, Y. J. Kaufman, T. Nakajima, F. Lavenu, I. Jankowiak, and A. Smirnmov, "AERONET-A Federated instrument network and data archive for aerosol characterization," Remote Sens. Environ., vol. 66 , pp. 1-16, 1998.

[24] H. Horvarth and A. Trier, "A study of the aerosol of Santiago de Chile-I. Light extinction coefficients," Atmos. Environ., vol. 27A, pp. 371-384, 1993.

[25] F. Kasten and M. T. Young, "Revised optical air mass tables and approximation formula," Appl. Opt., vol. 28, pp. 4735-4738, 1989.

[26] Y. J. Kaufman, A. Gitelson, A. Karnieli, E. Ganor, R. S Fraser, T. Nakajima, S. Mattoo, and B. N. Holben, "Size distribution and scattering phase function of aerosol particles retrieved from sky brightness measurements," J. Geophys. Res., vol. 99, pp. 10341-10356, 1994.

[27] V. I. Khvorostyanov and J. A. Curry, "A simple analytical model of aerosol properties with account for higroscopic growth 1. Equilibrium size spectra and cloud condensation nuclei activity spectra," J. Geophys. Res., vol. 104, pp. 2175-2184, 1999.

[28] M. D. King, D. M. Byrne, B. M. Herman, and J. A. Reagan, "Aerosol size distribution obtained by inversion of spectral optical depth measurements," J. Atmos. Sci., vol. 35, pp. 2154-2167, 1978. 
[29] M. D. King, "Sensitivity of constrained linear inversions to the selection of Lagrange multiplier," J. Atmos. Sci., vol. 39, pp. 1356-1369, 1982.

[30] M. D. King, Y. J. Kaufman, D. Tanré, and T. Nakajima, "Remote sensing of tropospheric aerosols from space: Past, present, and future," Bull. Amer. Meteorol. Soc., vol. 80, pp. 2229-2259, 1999.

[31] F. X. Kneizys, E. P. Shettle, L. W. Abreu, J. H. Chetwynd, G. P. Anderson, W. O. Gallery, J. E. A. Selby, and S. A. Clough, "Users Guide to Lowtran 7,” Tech. Rep. AFGL-TR-86-0177, Air Force Geophys. Lab., Hanscom AFB, MA, 1987.

[32] F. Li and D. Lu, "Features of aerosol optical depth with visibility grade over Beijing," Atmos. Environ., vol. 31, pp. 3413-3419, 1997.

[33] J. Lorente, A. Redaño, and X. De Cabo, "Influence of urban aerosol on spectral solar irradiance," J. Appl. Meteorol., vol. 33, pp. 406-414, 1994.

[34] J. A. Martínez-Lozano and M. P. Utrillas, "Insolación y nubosidad," in Atlas Climát. Comun. Valenciana (1961-1990). C.O.P.U.T. Valencia, Spain: Generalitat Valenciana, 1994.

[35] J. A. Martínez-Lozano, M. P. Utrillas, F. Tena, and V. Cachorro, "The parametrization of the atmospheric aerosol optical depth using the Angstrom power law," Solar Energy, vol. 63, pp. 303-311, 1998.

[36] J. A. Martínez-Lozano, M. P. Utrillas, and F. Tena, "Atmospheric aerosol optical depth from spectral irradiance measurements at ground level," Ann. Fís., vol. 94, pp. 103-107, 1998.

[37] — , "Retrieval of the aerosol size distribution from spectroradiometer measurements at a coastal site in the Mediterranean sea," Int. J. Remote Sensing, vol. 20, pp. 2167-2182, 1999

[38] —_ "A new inversion algorithm to retrieve instantaneous values for the aerosol optical depth from spectral irradiance measurements," IEEE Trans. Geosci. Remote Sensing, vol. 38, pp. 579-586, Jan. 2000.

[39] K. K. Moorthy, P. B. Nair, and B. V. K. Murthy, "Size distribution of coastal aerosols: Effects of local sources and sinks," J. Appl. Meteorol., vol. 30, pp. 844-852, 1991 .

[40] S. Nann and C. Riordan, "Solar spectral irradiance under clear and cloudy skies: Measurements and a semiempirical model," J. Appl. Meteorol., vol. 30, pp. 447-462, 1991.

[41] J. Piazzola and S. Despiau, "Contribution of marine aerosols in the particle size distributions observed in Mediterranean coastal zone," Atmos. Environ., vol. 31, pp. 2991-3009, 1997.

[42] R. Pedrós, M. P. Utrillas, J. A Martínez-Lozano, and F. Tena, "Values of broad-band coefficients in a Mediterranean coastal site," Solar Energy, vol. 66, pp. 11-20, 1999.

[43] J. N. Porter and A. D. Clarke, "Aerosol size distribution models based on in situ measurements," J. Geophys. Res., vol. 102, pp. 6035-6045, 1997.

[44] J. S. Reid, T. F. Eck, S. A. Christopher, P. V. Hobbs, and B. Holben, "Use of the Angstrom exponent to estimate the variability of optical and physical properties of aging smoke particles in Brazil," J. Geophys. Res., vol. 104, pp. $27473-27489,1999$.

[45] L. A. Remer and Y. J. Kaufman, "Dynamic aerosol model: Urban/industrial aerosol," J. Geophys. Res., vol. 103, pp. 13 859-13 871, 1998.

[46] L. A. Remer, Y. J. Kaufman, and B. N. Holben, "Interannual variation of ambient aerosol characteristics on the coast of the United States," $J$. Geophys. Res., vol. 104, pp. 2223-2231, 1999.

[47] L. A. Remer, Y. J. Kaufman, B. N. Holben, A. M. Thompson, and D. McNamara, "Biomass burning aerosol size distribution and modeled optical properties," J. Geophys. Res., pp. 31 879-31 891, 1998.

[48] C. Riordan, D. Myers, M. Rymes, M. Hulstrom, W. Marion, C. Jennings, and C. Whitaker, "Spectral solar radiation data base at SERI," Solar Energy, vol. 42, pp. 67-79, 1989

[49] P. Russell, P. J. Livingston, E. Dutton, R. Pueschel, J. Reagan, T. DeFoor, M. Box, D. Allen, P. Pilewskie, B. Herman, S. Kinne, and D. Hofmann, "Pinatubo and pre-Pinatubo optical depth spectra: Mauna Loa measurements, comparisons inferred particle size distributions, radiative effects, and relationships to lidar data," J. Geophys. Res., vol. 98, pp. 22 969-22985, 1993.

[50] S. K. Satheesh, V. Ramanathan, X. Li-Jones, J. M. Lobert, I. A. Podgorny, J. M. Prospero, B. N. Holben, and N. G. Loeb, "A model for the natural and anthropogenic aerosols over the tropical Indian Ocean derived from Indian Ocean experiment data," J. Geophys. Res., vol. 104, pp. 27421-27440, 1999 .

[51] B. Schmid, C. Mätzler, A. Heimo, and N. Kämpfer, "Retrieval of optical depth and particle size distribution of tropospheric and stratospheric aerosols by means of sun photometry," IEEE Trans. Geosci. Remote Sensing, vol. 35, pp. 172-182, Jan. 1997.

[52] W. Schneider, G. K. Moortgat, G. S. Tyndall, and J. P. Burrows, "Absorption cross-section of the $\mathrm{NO}_{2}$ in the UV and visible region (200-700 nm) at 298 K," J. Photochem. Photobiol., vol. 40, pp. 195-217, 1987.
[53] J. D. Spinhirne and M. D. King, "Latitudinal variation of spectral optical thickness and columnar size distribution of the El Chinchón stratospheric aerosol layer," J. Geophys. Res., vol. 90, pp. 10607-10619, 1985.

[54] D. Tanré, C. Devaux, M. Herman, R. Santer, and J. Y. Gac, "Radiative properties of desert aerosols by optical grund-based measurements at solar wavelength," J. Geophys. Res., vol. 93, pp. 14 223-14 231, 1988.

[55] I. Tegen, P. Hollrig, M. Chin, I. Fung, D. Jacob, and J. Penner, "Contribution of different aerosol especies to the global aerosol extinction opthical thickness: Estimates from model results," J. Geophys. Res., vol. 102, pp. 23 895-23 915, 1997.

[56] M. P. Utrillas, "Estudio de aerosoles a partir de medidas de irradiancia solar spectral," Ph. dissertation, Valencia Univ., Valencia, Spain, 1995.

[57] M. P. Utrillas, J. A. Martínez-Lozano, V. E. Cachorro, F. Tena, and S. Hernandez, "Comparison of aerosol optical thickness retrieval from spectroradiometer measurements and from two radiative transfer models," Solar Energy, vol. 68, pp. 197-205, 2000.

[58] A. M. J. Van Eijk and G. De Leeuw, "Modeling aerosol particle size distribution over the North sea," J. Geophys. Res., vol. 97, pp. 14417-14 429, 1991.

[59] B. Vasilyev, A. Leyva-Contreras, A. Muhlia Velazquez, R. Peralta, L. S. Ivlev, A. P. Kovalenko, A. V. Vasilyev, and V. M. Jukov, "Spectral optical properties of the polluted atmosphere of Mexico City (spring-summer 1992)," J. Geophys. Res., vol. 100, pp. 26 027-26044, 1995.

[60] Jukov and WMO, "Report on the measurements of atmospheric turbidity in BAPMoN," GAW Rep. 94, 1994.

[61] G. Yamamoto and M. Tanaka, "Determination of aerosol size distributions from spectral attenuation measurements," Appl. Opt., pp. 447-453, 1969.

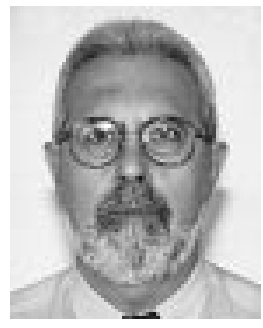

José A. Martínez-Lozano received the M.Sc. and $\mathrm{Ph} . \mathrm{D}$. degrees in physics from the University of Valencia, Valencia, Spain, in 1975 and 1983, respectively.

He currently teaches physics at the University of Valencia, where, among other subjects, he has specialized in atmospheric radiative transfer. $\mathrm{He}$ is also leading the Solar Radiation Group and the Department of Thermodynamics at the University of Valencia. One of the main interests of the group is the validation of satellite measurements employing sensors on the earth surface. His research interests at the present are in the study of optical properties of atmospheric aerosols.

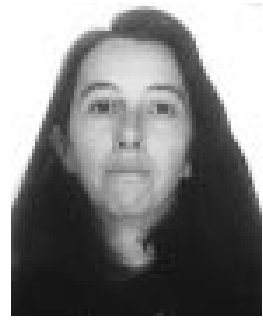

M. Pilar Utrillas received the M.Sc. and Ph.D. degrees, both from the University of Valencia, Valencia, Spain, in 1989 and 1995, respectively.

She is currently a Member of the Solar Radiation Group, University of Valencia, and has specialized also in radiation transfer codes and in solar spectral and integral instrumentation. Her main investigative work has been focused on the study and analysis of atmospheric aerosols and their influence on solar radiation reaching the Earth's surface. She also teaches thermodynamics and atmospheric radiative transfer at the University of Valencia.

Fernando Tena received the M.Sc. and Ph.D. degrees both from the University of Valencia, Valencia, Spain, in 1975 and 1982, respectively.

He currently teaches physics and renewable energy at the University of Valencia, and his research work has been focused on in the solar radiation area considering initially the whole integrated solar spectrum and reducing finally the interest to the UV range, particularly the UVB and its biological effects with emphasis on human responses. He is also a Member of the Solar Radiation Group, University of Valencia. 


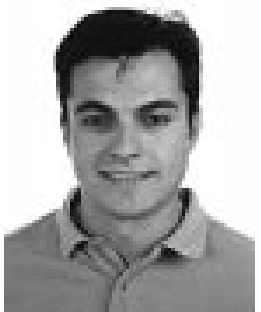

Roberto Pedrós received the M.Sc. degree in physics in 1995 from the University of Valencia, Valencia, Spain, where is currently pursuing the Ph.D. degree in physics with the Solar Radiation Group.

His research focuses on spectral solar radiation reaching the Earth's surface and its relationship with atmospheric aerosols. He specializes in using radiative transfer codes and in using and maintaining instrumentation for radiometry. He also teaches physics and runs atmospheric radiative transfer laboratory sessions for undergraduates at the University

of Valencia

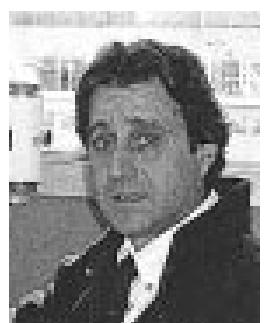

José V. Boscá received the M.Sc. degree in physics from the University of Valencia, Valencia, Spain, in 1975, and the Ph.D. degree in in physics from the Polytechnical University of Valencia, in 1995.

After several years teaching mathematics in a high school, he continued with educational tasks, teaching physics for engineers as a Lecturer with the Polytechnical University of Valencia. He is currently teaching and researching as an Associate Professor in the Department of Applied Physics, Polytechnical University of Valencia. His research interests are in measuring solar irradiances in narrow bands of spectrum in order to understand atmospheric processes and develop parameterized models.

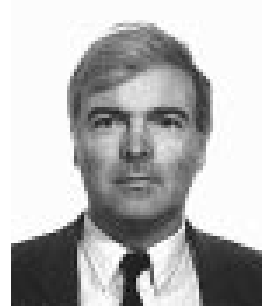

Jerónimo Lorente received the M.Sc. and Ph.D. degrees in physics from the University of Barcelona, Barcelona, Spain, in 1971 and 1977, respectively.

$\mathrm{He}$ is currently Professor of Atmospheric Physics with the University of Barcelona, and is also Spanish National Delegate in the COST 713 European action on UVB Forecasting. His research has been devoted to the solar radiation field, mainly in the turbidity and urban aerosol influences on UV particles.

ducing finally the interest to the solar spectral. He is also a Member of the Sola Radiation Group at the University of Valencia, and teaches thermodynamics and renewable energy at the Polytechnical University of Valencia. 